Review

\title{
Overview of Explainable Artificial Intelligence for Prognostic and Health Management of Industrial Assets Based on Preferred Reporting Items for Systematic Reviews and Meta-Analyses
}

\author{
Ahmad Kamal Mohd Nor ${ }^{1, *(\mathbb{D})}$, Srinivasa Rao Pedapati ${ }^{1}\left(\mathbb{D}\right.$, Masdi Muhammad $^{1}$ and Víctor Leiva $^{2}(\mathbb{D}$ \\ 1 Mechanical Department, Universiti Teknologi Petronas, Seri Iskandar 32610, Malaysia; \\ srinivasa.pedapati@utp.edu.my (S.R.P.); masdimuhammad@utp.edu.my (M.M.) \\ 2 School of Industrial Engineering, Pontificia Universidad Católica de Valparaíso, Valparaíso 2362807, Chile; \\ victor.leiva@pucv.cl \\ * Correspondence: ahmad_18002773@utp.edu.my
}

check for

updates

Citation: Nor, A.K.M.; Pedapati, S.R.; Muhammad, M.; Leiva, V. Overview of Explainable Artificial Intelligence for Prognostic and Health

Management of Industrial Assets Based on Preferred Reporting Items for Systematic Reviews and

Meta-Analyses. Sensors 2021, 21, 8020. https://doi.org/10.3390/s21238020

Academic Editor: Alexander Wong

Received: 19 October 2021

Accepted: 23 November 2021

Published: 1 December 2021

Publisher's Note: MDPI stays neutral with regard to jurisdictional claims in published maps and institutional affiliations.

Copyright: (C) 2021 by the authors Licensee MDPI, Basel, Switzerland. This article is an open access article distributed under the terms and conditions of the Creative Commons Attribution (CC BY) license (https:// creativecommons.org/licenses/by/ $4.0 /)$.

\begin{abstract}
Surveys on explainable artificial intelligence (XAI) are related to biology, clinical trials, fintech management, medicine, neurorobotics, and psychology, among others. Prognostics and health management (PHM) is the discipline that links the studies of failure mechanisms to system lifecycle management. There is a need, which is still absent, to produce an analytical compilation of PHM-XAI works. In this paper, we use preferred reporting items for systematic reviews and meta-analyses (PRISMA) to present a state of the art on XAI applied to PHM of industrial assets. This work provides an overview of the trend of XAI in PHM and answers the question of accuracy versus explainability, considering the extent of human involvement, explanation assessment, and uncertainty quantification in this topic. Research articles associated with the subject, since 2015 to 2021, were selected from five databases following the PRISMA methodology, several of them related to sensors. The data were extracted from selected articles and examined obtaining diverse findings that were synthesized as follows. First, while the discipline is still young, the analysis indicates a growing acceptance of XAI in PHM. Second, XAI offers dual advantages, where it is assimilated as a tool to execute PHM tasks and explain diagnostic and anomaly detection activities, implying a real need for XAI in PHM. Third, the review shows that PHM-XAI papers provide interesting results, suggesting that the PHM performance is unaffected by the XAI. Fourth, human role, evaluation metrics, and uncertainty management are areas requiring further attention by the PHM community. Adequate assessment metrics to cater to PHM needs are requested. Finally, most case studies featured in the considered articles are based on real industrial data, and some of them are related to sensors, showing that the available PHM-XAI blends solve real-world challenges, increasing the confidence in the artificial intelligence models' adoption in the industry.
\end{abstract}

Keywords: AI; explainable deep learning; machine learning; PHM; PRISMA; reliability; sensing and data extraction; XAI

\section{Introduction}

\subsection{General Progress in Artificial Intelligence}

Artificial intelligence (AI) continues its extensive penetration into emerging markets, driven by untapped opportunities of the 21st century and backed by steady and sizeable investments. In the last few years, AI-based research shows much concentration in areas such as large-scale machine learning (ML), deep learning (DL), reinforcement learning, robotic, computer vision, natural language processing, and internet of thing [1].

According to the first AI experts report in the "One-hundred-year study on artificial intelligence", AI ability will be heavily embodied in education, healthcare, home robotics, 
safety, security, and transportation, as well as entertainment, in North American cities by the 2030s [1].

The increasing data volume [2] and breakthrough in ML, coupled with the pressing need to be more efficient and innovatively democratize AI to the global scene, are currently relevant. A survey conducted by McKinsey [3] (www.mckinsey.com, accessed on 25 November 2021) recorded an annual increase of 30\% in AI investment from 2010 to 2013 and 40\% from 2013 to 2016. In 2016, the total global investment amounted from 26 to 39 billion dollars by tech firms and external investments. In 2030, AI could potentially be valued up to 15 trillion dollars in global gross domestic product growth thanks to automation and product innovation, while reducing approximately seven trillion dollars in operational costs [4]. AI-driven technology leads to an incremental change in labor market requirement, where increasing technological ability, together with higher cognitive and social-emotional skills, are needed to support AI-based infrastructures, whereas manual and basic cognitive skills experience less demand [5].

$\mathrm{AI}$ is a technical discipline defined as the science of making computers do things that would require intelligence if done by humans [6]. The reasoning of AI imitates natural laws translated into working algorithms [7]. Some important fields in AI research include expert systems, consisting of rule-based reasoning, case-based reasoning, and fuzzy systems, along with ML models [8-10], such as an artificial neural network (ANN), support vector machine, DL, and heuristic algorithms [11,12]. The availability of the parallel graphics processing unit and open-source development tools unlock the door for literally everyone to solve technical challenges, sometimes surpassing human performance $[13,14]$. These abilities and specialized tools make AI so appealing in technically infused domains such as computer vision [13], healthcare [6], image processing [7], and reliability engineering [11].

\subsection{Artificial Intelligence in Prognostic and Health Management}

$\mathrm{ML}$, in general, and more specifically DL, are part of the reliability research landscape, including prognostic and health management (PHM) [15-17]. PHM provides guidelines and frameworks to safeguard the healthy state of assets. PHM minimizes risks, maintenance costs, and workload, thus optimizing maintenance activities. PHM is defined by standards of the Institute of Electrical and Electronics Engineers (IEEE) as "a maintenance and asset management approach utilizing signals, measurements, models, and algorithms to detect, assess, and track degraded health, and to predict failure progression" [18]. Accordingly, three types of PHM activities are distinguished: (i) prognostic, (ii) diagnostic, and (iii) anomaly detection. Prognostic is the action of determining the remaining useful life (RUL) or the leftover operational time of an asset before a failure [17]. Diagnostic is the action of classifying a failure and, to some extent, discovering the detailed root cause of this failure [19]. Anomaly detection consists of identifying unusual patterns going against the normal behavior of operational indicators [20].

A considerable part of the literature supports the idea of AI as being at the forefront in PHM studies [15,20]. To mention a few: (i) long short-term memory (LSTM) ANN was employed in [21] with degradation image to estimate the RUL of rotating machinery; (ii) a regression tree was used to predict the RUL of central heating and cooling plant equipment in [22]; (iii) the combination of logistic regression with L2 SVM was proposed for gas circulator unit prognostic [23,24]; (iv) random forest was utilized to diagnose fault for semiconductor equipment failure in [25]; (v) convolutional and fully connected layers with Softmax activation were considered in [26] to diagnose rotating machine issues; and (vi) gradient-boosted decision trees outperformed other methods in the anomaly detection of hard drives in [27].

\subsection{Black-Box Artificial Intelligence Problem}

Though very powerful, many AI methods are black boxes in nature, meaning that the inner mechanism to produce outputs in these methods are unknown $[28,29]$. Obviously, this opacity is an obstacle in AI penetration across many sensitive or high-stake areas such 
as banking, defense, finance, and medical areas, even in the common industry [30,31]. The end-users and experts of the domain in question need the assurance that the model's inner process is understandable [32]. Such an opaqueness adds operational and confidentiality hazards, bias, or nonethical outputs risks [33]. The lack of transparency discourages responsible exploitation of AI decisions [34], model troubleshooting [35], and improvement [32]. Moreover, it further complicates the question of responsibility ownership in the case of wrong decision [36]. Therefore, with the increasing scrutiny and regulation on AI usage, the need to make AI methods as transparent as possible is pressing. This includes the general data protection regulation in the European Union and the ethics guidelines for trustworthy AI presented by the European Commission High-Level Expert Group on AI [37-39].

\subsection{The Need for Explainable Artificial Intelligence}

Explainable artificial intelligence (XAI) is a discipline dedicated in making AI methods more transparent, explainable, and understandable to end-users, stakeholders, nonexperts, and non-stakeholders alike to nurture trust in AI. The growing curiosity in XAI is mirrored by the spike of interest in this search term since 2016 and the rising number of publications throughout the years [38].

The Defense Advanced Research Projects Agency (DARPA) developed the XAI Program in 2017, while the Chinese government announced the Development Plan for New Generation of Artificial Intelligence in the same year, both promoting the dissemination of XAI [40]. The general needs for XAI are as follows:

(i) Justification of the model's decision by identifying issues and enhancing AI models.

(ii) Obedience of the AI regulation and guidelines in usage, bias, ethics, dependability, accountability, safety, and security.

(iii) Permission for users to confirm the model's desirable features, promote engagement, obtain fresh insights into the model or data, and augment human intuition.

(iv) Allowance for users to better optimize and focus their activities, efforts, and resources.

(v) Support for the model development when it is not yet considered as reliable.

(vi) Encouragement for the cooperation between AI experts and external parties.

\subsection{Common XAI Approaches}

While there are many definitions linked to XAI, this work concentrates only on the most employed notions of interpretability and explainability. On the one hand, interpretability refers to the ability to provide human-understandable justification for the one's behavior. Thus, interpretable AI points to the model's structures which are transparent and readily interpretable. On the other hand, explainability describes an external proxy used to describe the behavior of the model. Hence, explainable AI refers to post-hoc approaches utilized for explaining a black-box model. The first definition explicitly distinguishes between black-box and interpretable models. The second definition takes a broader connotation where explainability is accented as a technical ability to describe any AI model in general and not only black-box identification.

XAI approaches are classified according to an explanation scope [41]. Intrinsic models are interpretable due to their simplicity such as in linear regression and logic analysis of data (LAD), while post-hoc approaches interpret more complex nonlinear models [32,33]. Examples of post-hoc approaches are local interpretable model-agnostic explanations (LIME) and Shapley additive explanations (SHAP).

An approach can be categorized as (i) AI-model specific or (ii) employable in any AI model or model agnostic [14,42]. Class activation mapping (CAM), for example, can only be utilized after CNN. Layer-wise relevance propagation (LRP) and gradient-weighted CAM may be employed in any gradient-based models.

Therefore, the explanation by the XAI model can either cater to local data instances or to the whole (global) dataset [41]. For example, SHAP may generate both local and global explanations, while LIME is only suitable for local explanation. 


\subsection{Review Motivation}

The main objective of this work is to present an overview of XAI applications in PHM of industrial assets by using preferred reporting items for systematic reviews and metaanalyses (PRISMA, available online: www.prisma-statement.org, accessed on 4 October 2021) guidelines [43]. PRISMA is an evidence-based guideline that ensures comprehensiveness, reducing bias, increasing reliability, transparency, and clarity of the review with minimum items [44,45]. PRISMA is a 27-checklist guideline that needs to be satisfied as best as possible for the best practice in systematic review redaction. However, in the systematic review presented in the present study, items 12, 13e, 13f, 14, 15, 18-22, and 24 of the PRISMA methodology were omitted as they were not dealt with here; see prisma-statement.org/PRISMAstatement/checklist.aspx (accessed on 19 November 2021) for details on these items.

The rationalities motivating the compilation of this review are the following:

(i) Global interest in XAI: According to our survey, the general curiosity toward XAI has surged since 2016 [14]. Figure 1 shows the interest expressed for the term "explainable $\mathrm{AI}^{\prime \prime}$ in Google searches, with 100 being the peak popularity for any term.

(ii) Specialized reviews: In the early years, several general surveys on XAI methods were written [32,34]. More recently, as the discipline grows, more specialized works emerged. Reviews on XAI have been related to drug discovery [31], fintech management [35], healthcare [30,33,36], neurorobotics [39], pathology [28], plant biology [37], and psychology [29]. Thus, it is necessary to produce an analytical compilation of PHM-XAI works, which is still absent.

(iii) PHM nature and regulation: PHM is naturally related to high-investment and safetysensitive industrial domains. Moreover, it is pressing to ensure the use of wellregulated AI in PHM. Hence, it is necessary for XAI to be promoted as much as possible and its know-how disseminated for the benefit of PHM actors.

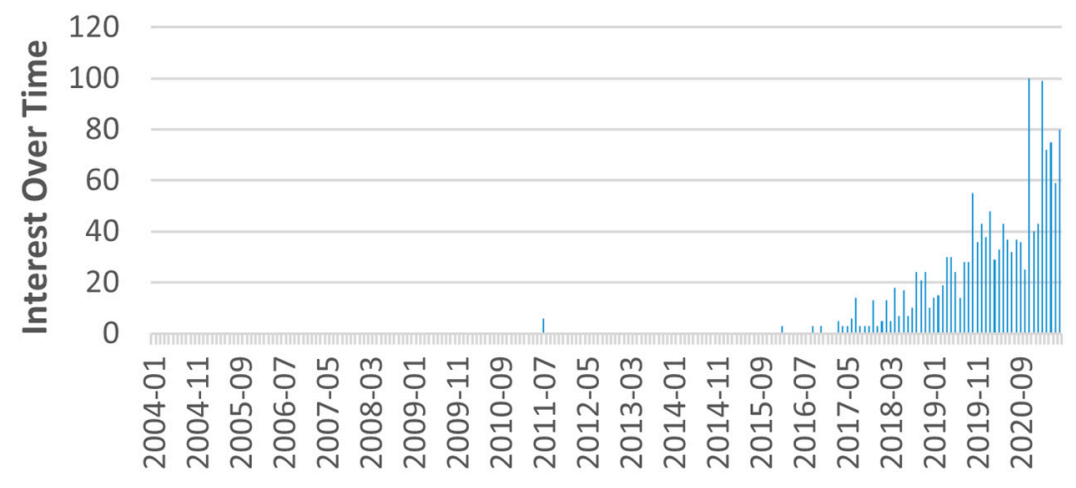

\section{Year \& Month}

Figure 1. Interest shown for the term "explainable $\mathrm{AI}^{\prime}$ in Google searches.

The review goals are achieved by addressing the following points:

(i) General trend: This is related to an overview of the XAI approach employed, the repartition of the mentioned methods according to PHM activities, and the type of case study involved.

(ii) Accuracy versus explainability power: According to DARPA, the model's accuracy performance is inverse to its explainability prowess [40].

(iii) XAI role: This must assist or overload PHM tasks.

(iv) Challenges in PHM-XAI progress: Crosschecks were done with the general challenges raised in $[14,32,34,38]$ associated with:

(a) The lack of explanation evaluation metrics.

(b) The absence of human involvement for enhancing the explanation effectivity.

(c) The omission of uncertainty management in the studied literature. 
The remainder of this paper is organized as follows: In Section 2, the methodology is introduced, followed by the results presentation in Section 3. Then, the discussion is elaborated in Section 4. Finally, the concluding remarks are presented in Section 5.

\section{Methodology}

\subsection{Framework}

A single person performed the search, screening, and data extraction of the articles considered in this study. Thus, no disagreement occurred in all the steps mentioned. Only peer-reviewed journal articles on PHM-XAI of industrial assets between 2015 and 2021 in English language were selected.

\subsection{Databases}

Five publication databases consisting of ScienceDirect of Elsevier (until 17 February 2021), IEEE Xplore (until 18 February 2021), SpringerLink (until 22 February 2021), Scopus (until 27 February 2021), and Association for Computing Machinery (ACM) Digital Library (until 28 May 2021) were explored. Advanced search was used, but since the database features are different, a specific strategy was adopted. In IEEE Xplore, search was conducted in the "abstract" and "document title" fields only as they are the most relevant options. The database also authorizes search within the obtained results in the "search within results" field. Wildcard was not used in IEEE Xplore even though it was permitted. Comprehensive search in the "title", "abstract", and "keywords" fields were performed in ScienceDirect and Scopus; "title", "abstract", and "author-specified keywords" fields for ScienceDirect; and "search within article title", "abstract", and "keywords" fields for Scopus. However, unlike Scopus, ScienceDirect does not support wildcard search; therefore, it was only employed in Scopus. In SpringerLink, the "with all the words" field was utilized altogether with wildcards. In ACM, both the ACM full-text collection and ACM guide for obtaining the literature were examined. The "Search within" option in the "title", "abstract", and "keywords" was executed with wildcard. Once performed, the screening of duplications was performed by using the Zotero software (www.zotero.org, accessed on 4 October 2021). The full research strategy is listed in Appendix A.

\subsection{Steps of Our Bibliographical Review}

The following screening steps were executed one after another for obtaining a result, with each screening step starting in the title, then the abstract, and next the keywords:

(S1) Verify whether the article type is research or not.

(S2) Exclude non-PHM articles by identifying absence of commonly employed PHM terms such as prognostic, prognosis, RUL, diagnostic, diagnosis, anomaly detection, failure, fault, or degradation.

(S3) Discard non-XAI articles by identifying absence of commonly used XAI terms which are explainable, interpretable, and AI.

(S4) Eliminate non-PHM-XAI articles by identifying the absence of both PHM and XAI terms as, respectively, indicated in steps (ii) and (iii) above.

(S5) Remove articles related to medical applications or network security.

Then, the context of the articles was examined on the remaining works for final screening and so to retain only the desired articles. The data extracted from the articles were gathered in a Microsoft Excel file with each column corresponding to each investigated variable. Directly retained variables were: "author", "publication year", "title", "publisher", and "publication/journal name". Further information extracted from the article context analysis is as follows:

(i) PHM activity category: This corresponds to either anomaly detection, prognostic, or diagnostic, with structural damage detection as well as binary failure prediction being considered as diagnostic.

(ii) XAI approach employed: This is related to the category of the XAI method. 
(iii) Recorded performance: This is associated with the reported result. Some papers clearly claim the comparability or the superiority of the proposed method over other tested methods. In the case where comparison was not conducted, the reported standalone results for accuracy, precision, F1 score, area under the receiving operating characteristic curve (AUC) score, area under precision-recall curve (PRAUC) score, or the Cohen kappa statistic score were referred to Table A4 in Appendix A and classified as either "bad", "fair", "good", and "very good". When mixed performance of good and very good was recorded for the same method, it was quantified as only "good". When a method was superior to the rest, it was classified as "very good" unless detailed as only "good". Some results were appreciated based on the problem at hand, for example using the mean square error (MSE), root mean square error (RMSE), and mean absolute error (MAE) as direct comparisons is not possible.

(iv) XAI role in assisting PHM task: This regards the role of XAI in strengthening PHM ability.

(v) Existence of explanation evaluation metrics: This is stated as presence or not of a metric.

(vi) Human role in PHM-XAI works: This is considered as existence of the mentioned role or not.

(vii) Uncertainty management: This is linked to if uncertainty management in any of the stages of the PHM or XAI approaches increases the possibility for adoption by user due to additional surety.

(viii) Case study type (real or simulated): Real was considered when the data of a case study came from a real mechanical device, whereas simulated was considered when data were generated utilizing any type of computational simulation.

\subsection{Outputs}

The outputs were presented in the following forms:

(i) Table: Selected and excluded articles with variables sought.

(ii) Pie chart: Summary of the PHM activity category, explanation metric, human role, and uncertainty management.

(iii) Column graph: Summary of the PHM-XAI yearly trend, XAI approach employed, recorded performance, and XAI role in assisting a PHM task.

\section{Results}

\subsection{Framework}

We selected 3048 papers from the databases according to the applied keywords with their respective number (absolute frequency) as shown in Table A3 of Appendix A. Note that 288 articles were screened out as duplicates. Out of the 2760 remaining, 25 papers were screened out as they are editorial papers or documents related to news. Then, 70 papers were selected according to criteria (S1)-(S5) described in Section 2.3 (steps of our bibliographical review) from the remaining 2735 articles. Lastly, only 35 papers were selected as other 35 articles were deemed not relevant with the reviewed topic after context verification. The final selected and excluded studies can be found, respectively, in Tables A1 and A2 of Appendix A.

\subsection{PRISMA Flow Diagram}

As mentioned, the selected and excluded articles based on the criteria for inclusion are disclosed, respectively, in Tables A1 and A2. The PRISMA flow diagram of the selection and screening processes is displayed in Figure 2.

The repartition of the selected articles' PHM domain as well as their publisher are presented in Figures 3 and 4, respectively. The repartition of the excluded articles' PHM domain as well as their publisher are presented in Figures 5 and 6, respectively. As noted from Figure 3, diagnostic research holds the biggest share in PHM-XAI articles. Figure 4 illustrates IEEE and Elsevier publishers as being the biggest sources of the accepted articles. 


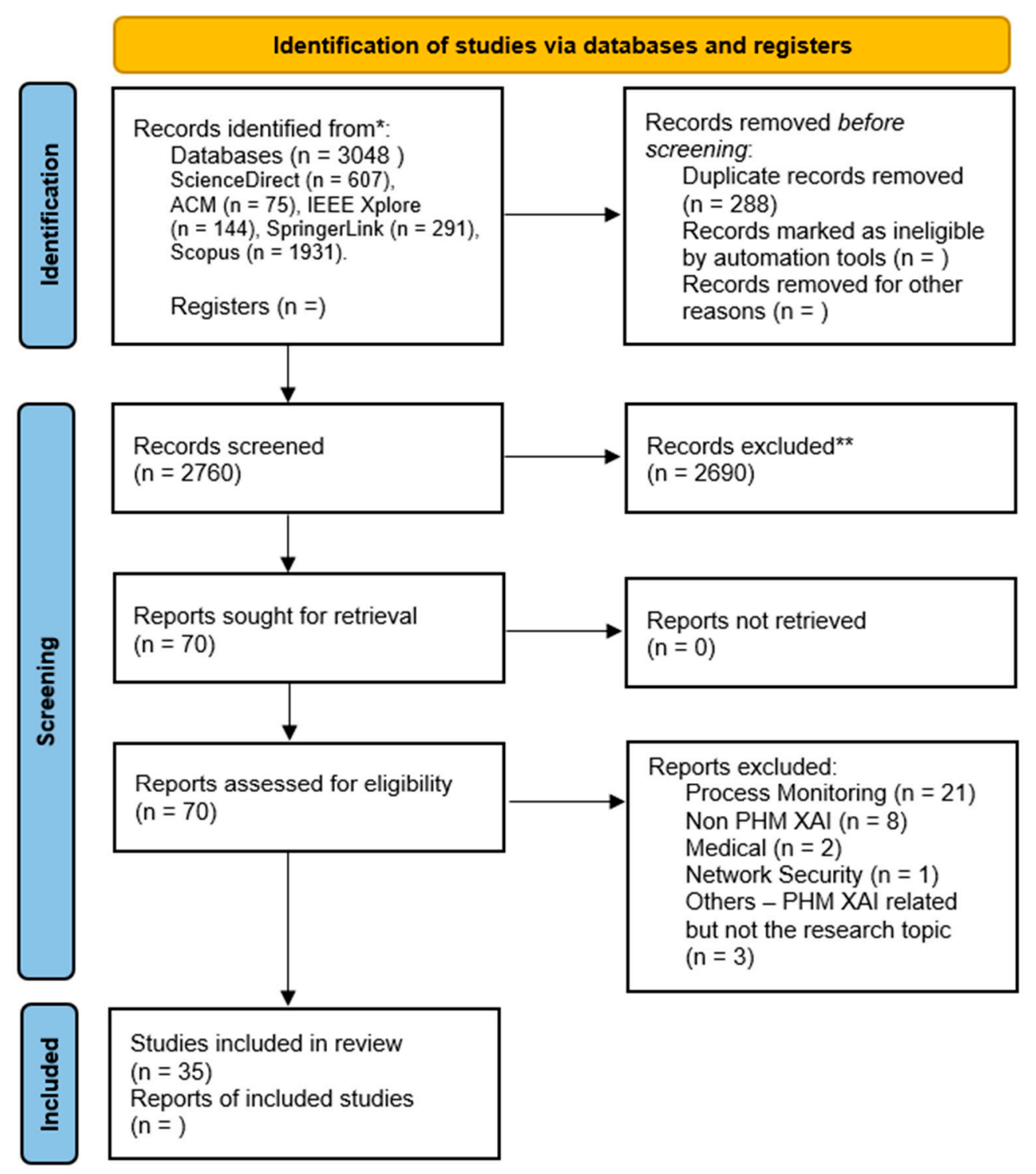

Figure 2. PRISMA flow diagram of the search strategy for our review on PHM-XAI.3.3 ("** indicates that " $n=$ " in the database field corresponds to the total number of records from all the databases specified below; and "**" states that the Zotero software was used for duplication analysis).

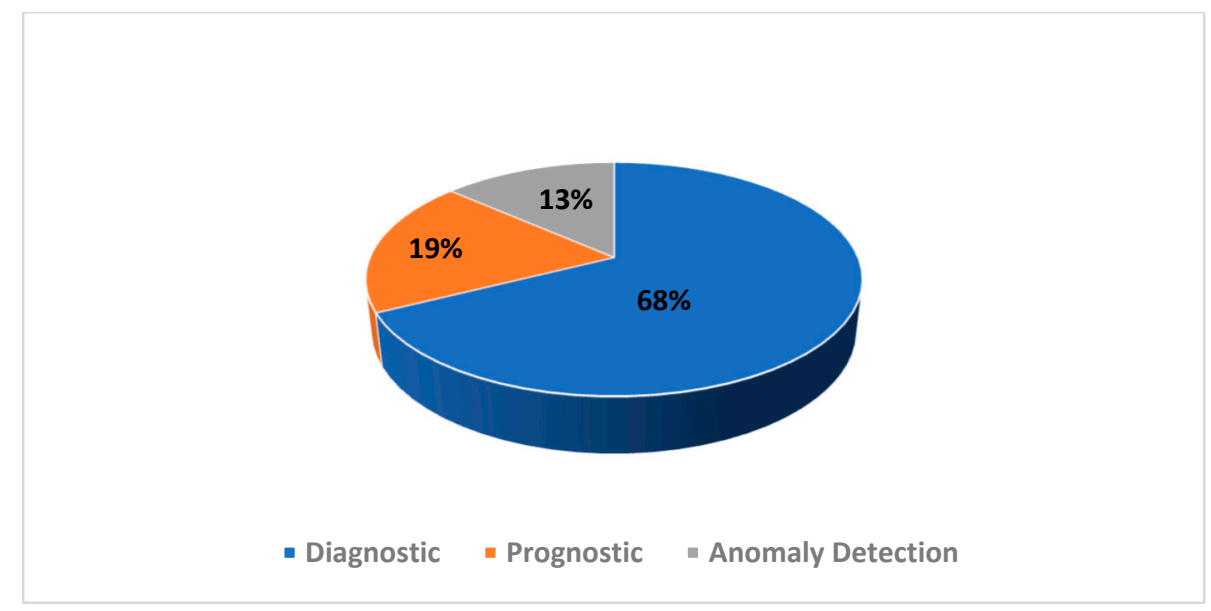

Figure 3. Distribution of PHM tasks for the selected articles. 


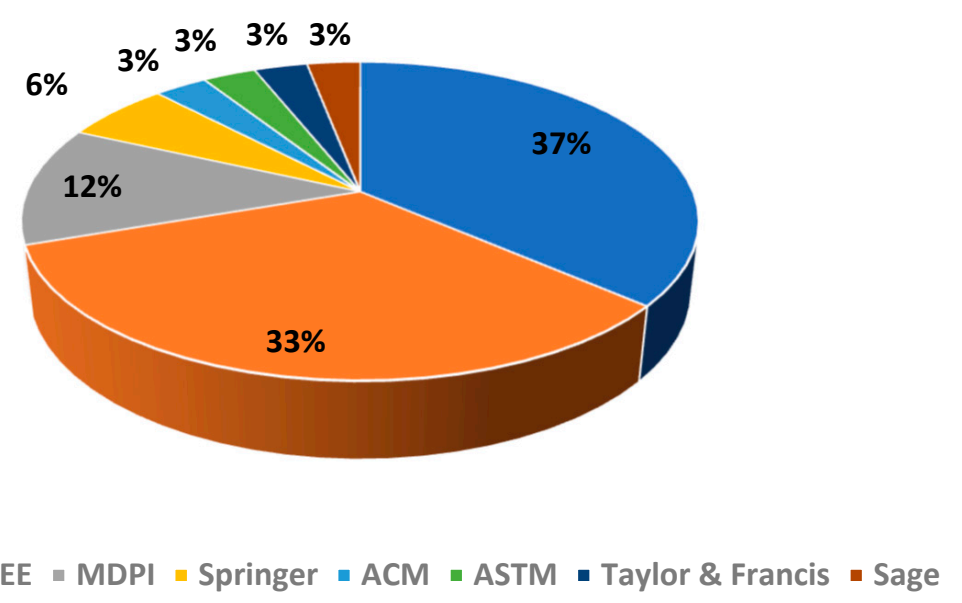

Figure 4. Distribution of the selected articles according to the indicated publisher.

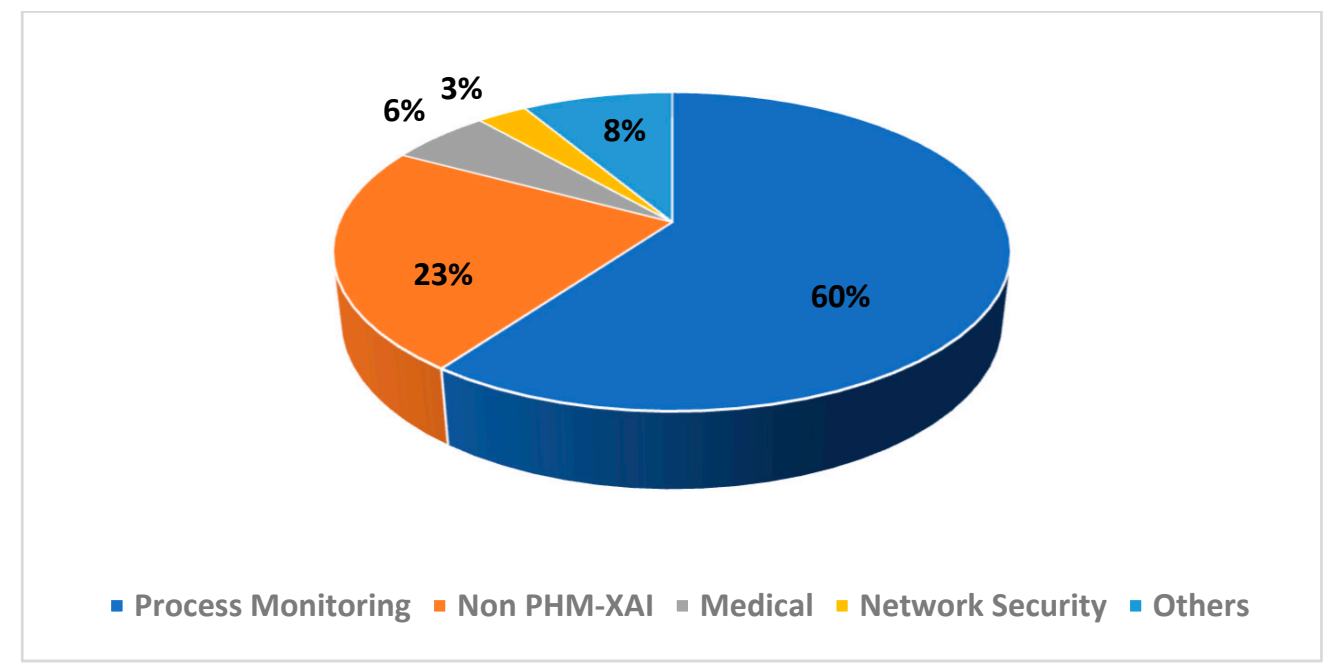

Figure 5. Distribution of the excluded articles according to the topic.

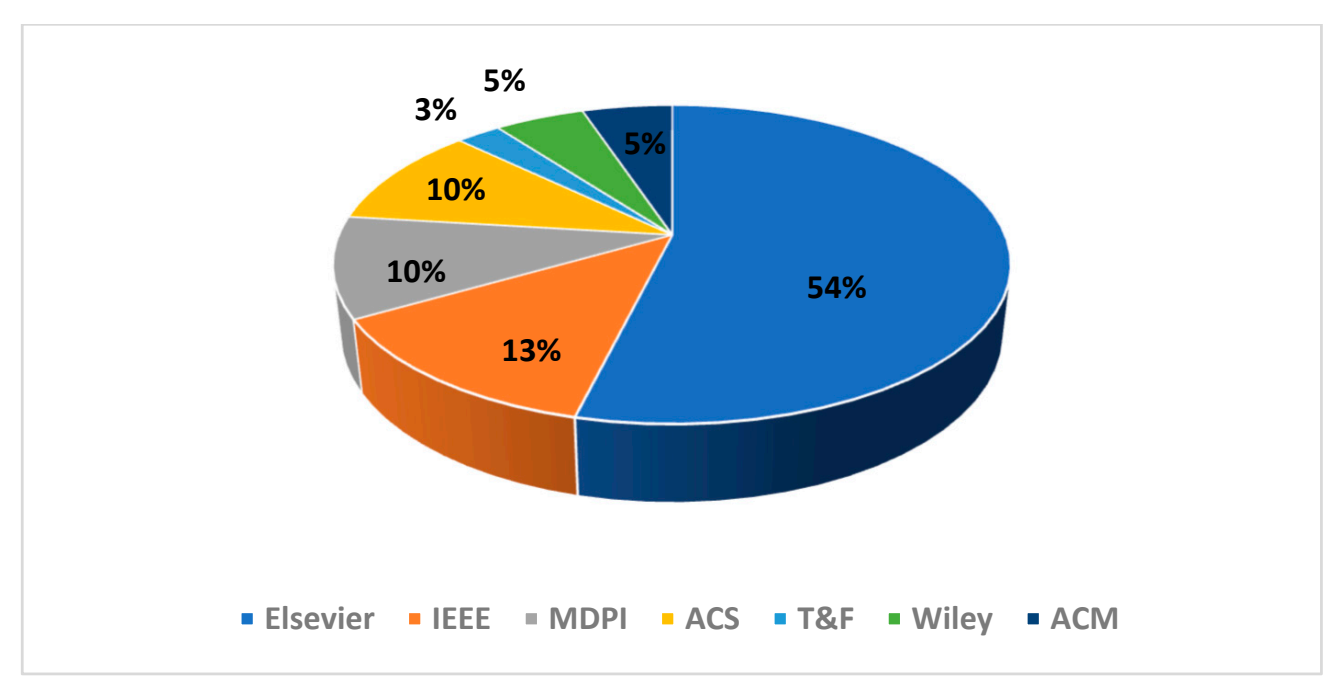

Figure 6. Distribution of the excluded articles according to the publisher. 
Numerous unselected publications, though related to XAI, correspond to process monitoring research, as shown in Figure 5. These works were excluded as they are closely related to quality context rather than failure of products. Some works are focused on products instead of the industrial assets. Furthermore, the anomaly described is seldom associated with process disturbance rather than failure degradation. Studies concerning the network security were also omitted. In addition, most of the excluded articles come from the Elsevier and IEEE publishers as confirmed by Figure 6, further showing that these publishers are the main sources of many XAI-related articles.

\section{Discussion}

\subsection{General Trend}

As shown in Table A1 of Appendix A and summarized in Figure 7, the accepted articles according to the publication year show an upward trend, with a major spike in 2020, indicating a growing interest in XAI from the PHM researchers. However, the number of accepted articles is still very small, reflecting the infancy state of XAI in PHM, compared to other research fields such as cyber, defense, healthcare, and network securities. XAI is especially beneficial to the latter domains as it helps in fulfilling their primary functions of protecting lives and assets-contrasted to PHM research, where it is predominantly focused in facilitating financial decision making. In the healthcare field, for example, the efforts to evaluate explanation quality are presently an active topic, which is not the case of PHM [46]. The understanding of XAI is also limited in PHM, partly due to comprehensible distrust in using $\mathrm{AI}$ in the first place, compounded with the amount of investment needed to build AI systems that is yet to be proven in real life. In fact, manufacturing and energy sectors, associated closely with PHM, are amongst the slowest in adopting AI [47]. Thus, AI only thrives in PHM research. In brief, more exposure and advocation of XAI in PHM are needed to nurture trust in the AI usage, improving day to day the operational efficiency and enabling the overall safeguard of industrial assets and lives.

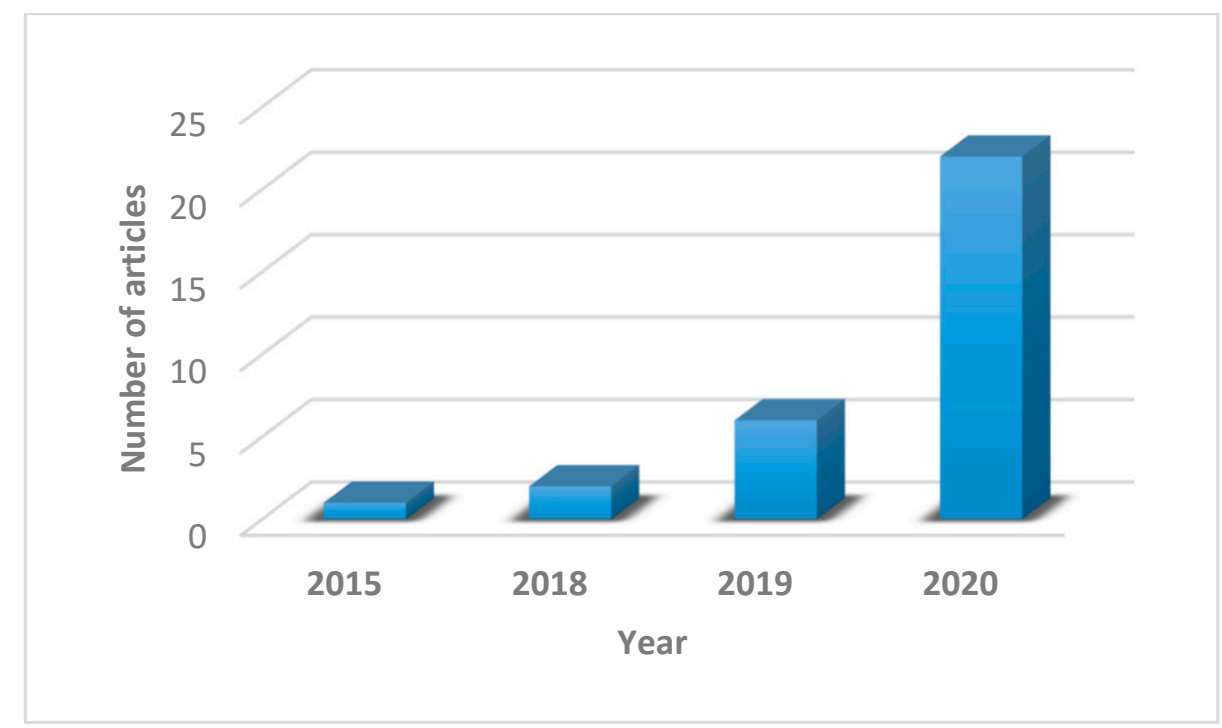

Figure 7. Distribution of the selected articles according to the indicated year.

Note that $70 \%$ of the included PHM-XAI works come from ScienceDirect and IEEE Xplore as testified by Figure 4. Most of the excluded articles in the final stage also come from the mentioned databases as shown in Figure 6. These observations suggest that these two databases concentrate XAI-related works. It is commendable for a specialized journal in other publishers to promote the use of XAI in PHM through dedicated symposiums and special issues, which are still scarce. 


\subsection{XAI}

Interpretable models, rule- and knowledge-based models, and the attention mechanism are the most employed methods as illustrated in Figure 8. These methods existed well before XAI become mainstream. Then, their implementations became well documented and common. Interpretable approaches consist of linear models widely used before the introduction of nonlinear models. Rule- and knowledge-based models possess the traits of expert systems which became widespread earlier and led to the popularity of AI [48]. The attention mechanism was developed in the image recognition field to improve classification accuracy [49].

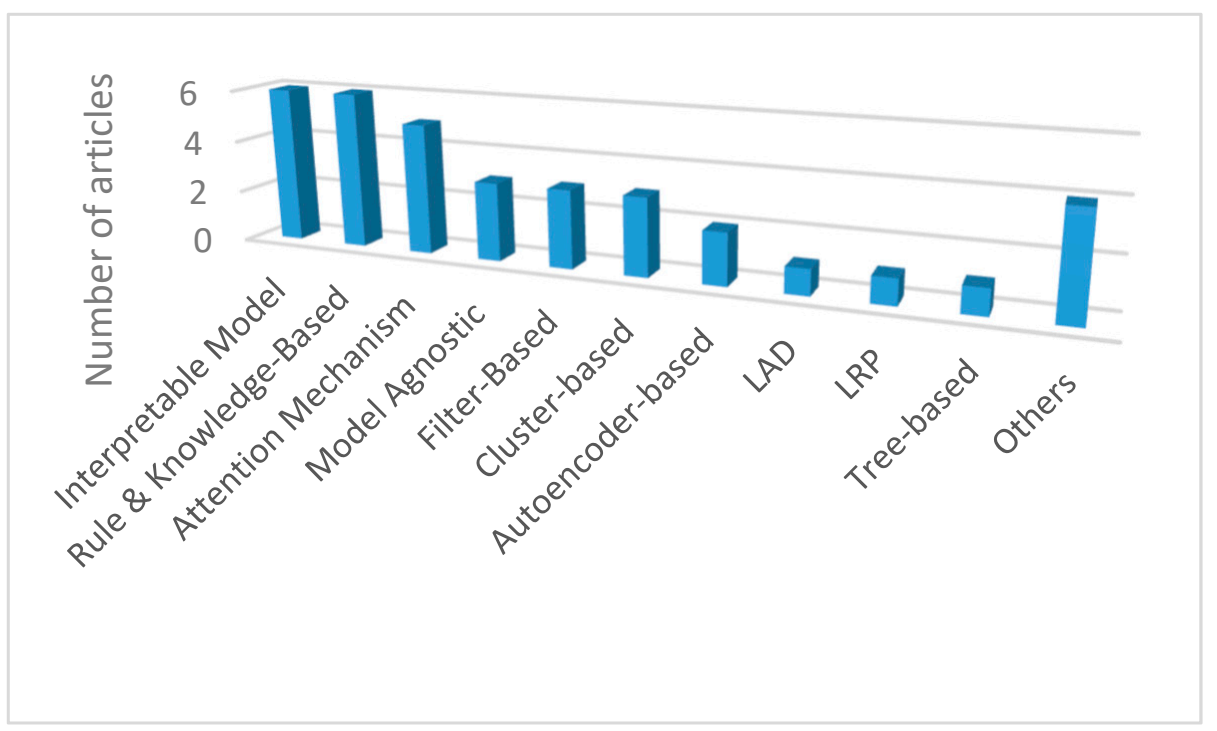

Figure 8. Distribution of the XAI approach type in the selected articles.

Other techniques such as model agnostic explainability and LRP are less explored but are anticipated to permeate in the future due to their nature. They could be used with any black-box models. Furthermore, the performance of the AI models is not altered by these techniques. Model agnostic acts as an external method to the model to be explained while $\mathrm{LRP}$ requires only the gradient flow of the network. LAD is another interesting technique due to its potential combination with fault tree analysis that is seldom utilized in complex risk management such as in the aerospace and nuclear industries. The lack of coverage in LAD entails more investigation from the researchers on this topic.

The diagnostic domain occupies the majority share amongst the accepted works as presented in Figure 3. Looking at the XAI-assisted PHM column in Table A1 of Appendix A, it can be deduced that XAI boosts diagnostic ability. Drawing a parallel between the information from Figure 3 and Table A1, it may be inferred that XAI is particularly appealing to diagnostic as it can be applied directly as a diagnostic tool or in addition to other methods. XAI could provide additional incentive to diagnostic whose main objective is to discover the features responsible for the failure as shown in Figure 9. This interesting point signifies that the diagnostic tasks in these papers are dependent on XAI. Therefore, XAI is not only a supplementary feature in diagnostics but also an indispensable tool. The same phenomenon is observed in anomaly detection as presented in Figure 9. Knowing the cause of anomaly could potentially avoid false alarms, preventing resource wastage. Thus, XAI might be employed to execute PHM tasks and explain them. 


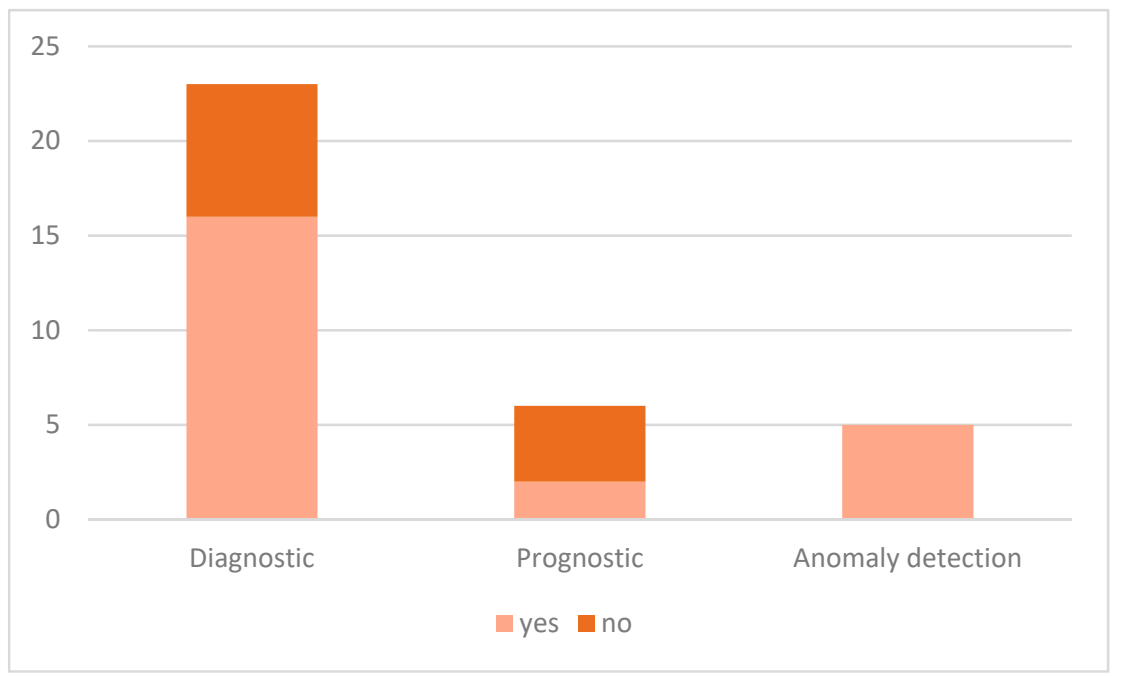

Figure 9. Distribution of the XAI assistance in the indicated PHM task.

Table A1 reveals that some XAI approaches directly assist the PHM tasks achieving excellent performance. Furthermore, the recorded PHM performance of both XAI and non-XAI methods (works that depend on XAI for explanation only) are mostly very good for diagnostics and prognostics, as depicted in Figure 10. In brief, no bad results were recorded as confirmed by Figure 10. Whether the results are contributed by XAI or not, it can safely be concluded that explainability does not affect the tasks' accuracy in the studied works. The outcomes and reported advantage of XAI as a PHM tool are important steps in eradicating the skepticism and mistrust of the industry in the AI usage. These facts might intensify the assimilation of $\mathrm{AI}$ in the industry.

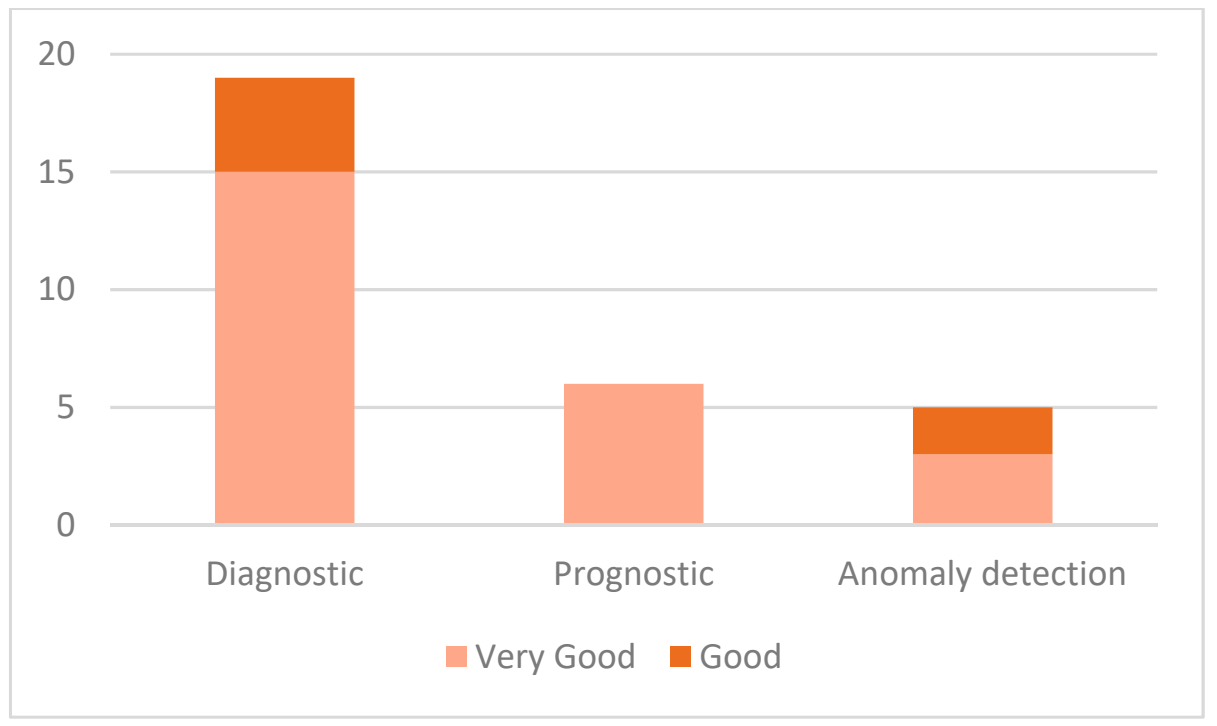

Figure 10. Distribution of the performance of AI models according to the indicated task.

\subsection{PHM}

Real industrial data are mostly used in case studies to demonstrate the effectiveness of XAI as reflected in Figure 11a. Furthermore, the studies reflect the outreach of XAI in diverse technical sectors such as aerospace, automotive, energy, manufacturing, production, and structural engineering fields. These positive outlooks prove that the available PHMXAI combinations are suitable to solve real-world industrial challenges with at least a good performance, boosting the confidence in the AI models' adoption. 


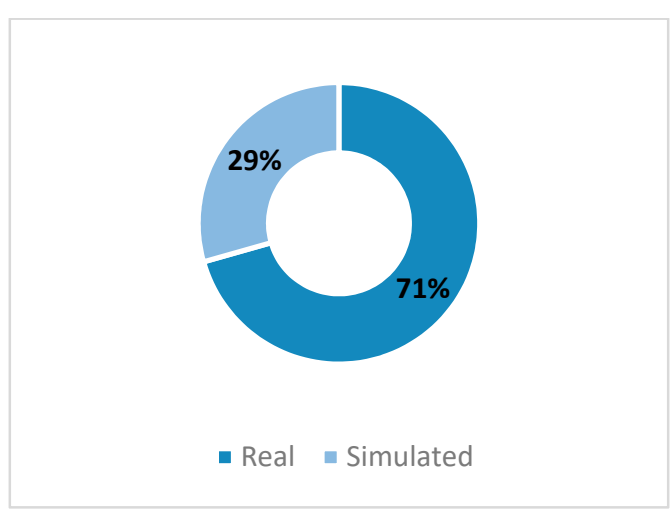

(a)

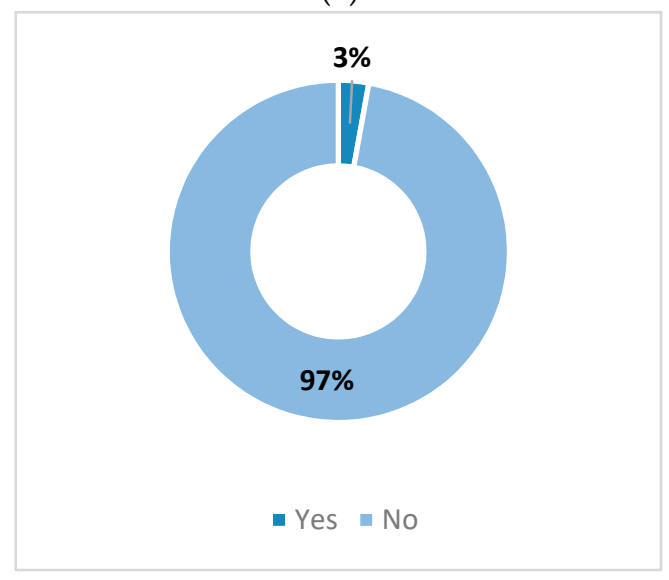

(c)

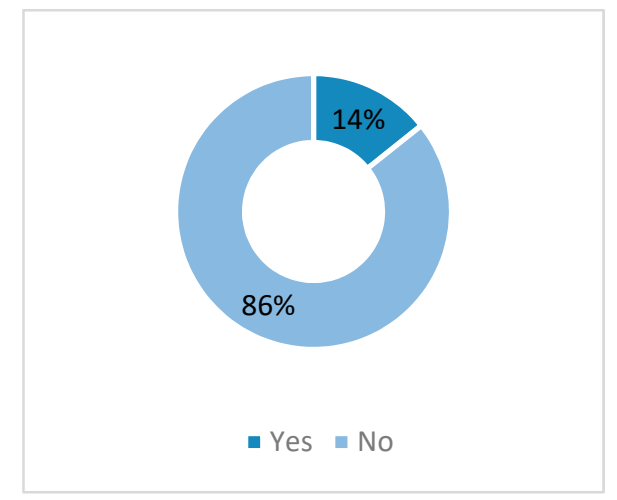

(b)

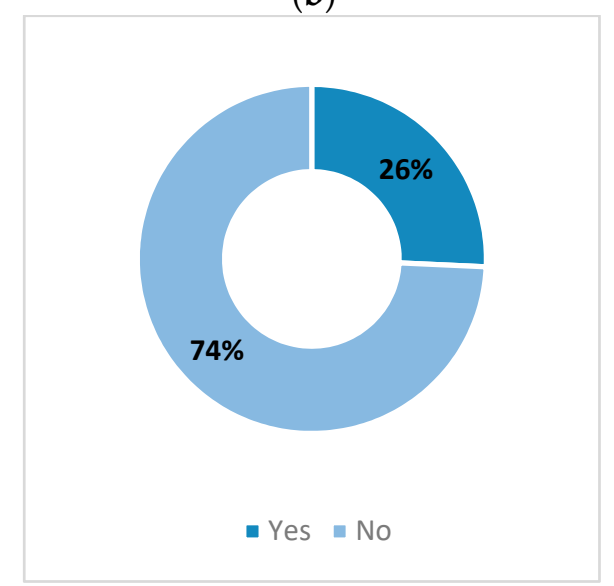

(d)

Figure 11. (a) Distribution of the type of case study in the selected articles; (b) distribution of human involvement (yes/no) in the selected articles; (c) distribution of explanation metric inclusion (yes/no) in the selected articles; and (d) distribution of uncertainty management inclusion (yes/no) in the selected articles.

\subsection{Lack of Current Studies}

\subsubsection{Human Role in XAI}

A very small role was played by humans in the examined works as illustrated in Figure $11 \mathrm{~b}$. Human participation is vital for evaluating the generated explanation, as it is intended to be understood by them. This involvement helps in the assimilation of other human-related sciences to PHM-XAI such as human reliability engineering (HRA), psychology, or even healthcare, further enriching this new field [50]. Furthermore, human involvement is encouraged for the development of interactive AI, where the expert's opinion strengthens or debates the generated explanation, presenting an additional guarantee in AI performance.

\subsubsection{Explainability Metrics}

Note that the usage of explanation evaluation metrics is nearly nonexistent as presented in Figure 11c. The explanation evaluation method engineered for the PHM usage is practically absent according to our study. These metrics are vital to the researchers and developers when evaluating the explanation quality. It is recommended that adequate assessment metrics for PHM explanation, considering security and safety risk, maintenance cost, time, and gain are developed and adopted. Such metrics should require the collaboration of all PHM actors to satisfy the need of each level of hierarchy. From this angle, XAI experts could be inspired by the work performed in the HRA domain, which studies the human-machine interaction in reliability perspective [50]. An overview of explanation metrics and methods is presented in [51], whereas the effectiveness of explanation from 
experts to nonexperts is studied in [52], and a metric to assess the quality of medical explanation was proposed in [53].

\subsubsection{Uncertainty Management}

Various types of uncertainty management methods are adopted in different stages in the studied works on the PHM-XAI area as detailed in Table A1. Nevertheless, note that, in Figure 11d, much improvement is still required in this area. Uncertainty management gives additional surety to users to adopt PHM-XAI methods compared to point estimation models. Furthermore, uncertainty quantification is vital to provide additional security to AI infrastructure against adversarial examples, either unintentionally or motivated by the attack. This quantification might minimize the risk of wrong explanation being produced from unseen data due to adversarial examples.

\section{Conclusions}

In this work, a state-of-the-art systematic review on the applications of explainable artificial intelligence linked to prognostics and health management of industrial assets was compiled. The review followed the guidelines of preferred reporting items for systematic reviews and meta-analyses (PRISMA) for the best practice in systematic review reporting. After applying our criteria for inclusion to 3048 papers, we selected and examined 35 peer-reviewed articles, in the English language, from 2015 to 2021, about explainable artificial intelligence related to prognostics and health management, to accomplish the review objectives.

Several interesting findings were discovered in our investigation. Firstly, this review found that explainable artificial intelligence is attracting interest in the domain of prognostics and health management, with a spike in published works in 2020, though still in its infancy phase. The interpretable model, rule- and knowledge-based methods, and attention mechanism are the most widely used explainable artificial intelligence techniques applied in the works of prognostics and health management. Secondly, explainable artificial intelligence is central to prognostics and health management, assimilated as a tool to execute such tasks by most diagnostic and anomaly detection works, while simultaneously being an instrument of explanation. Thirdly, it was discovered that the performance of prognostics and health management is unaltered by explainable artificial intelligence. In fact, the majority of works that related both approaches achieved excellent performance while the rest produced only good results. However, there is much work to be conducted in terms of human participation, explanation metrics, and uncertainty management, which are nearly absent.

This overview discovered that most real, industrial case studies belonging to diverse technical sectors are tested to demonstrate the effectiveness of explainable artificial intelligence, signifying the outreach and readiness of general artificial intelligence and explainable artificial intelligence to solve real and complex industrial challenges.

The implications of this study are the following:

(i) PHM-XAI progress: Much unexplored opportunity is still available for prognostics and health management researchers to advance the assimilation of explainable artificial intelligence in prognostics and health management.

(ii) Interpretable models, rule- and knowledge-based models, and attention mechanism: These are the most widely used techniques and more research involving other approaches could give additional insight into the prognostics and health management community in terms of performance, ease of use, and flexibility of the explainable artificial intelligence method.

(iii) XAI as PHM tool and instrument of explanation: explainable artificial intelligence could be preferred or required within prognostics and health management compared to standalone methods. 
(iv) PHM performance uninfluenced by XAI: The confidence of prognostics and health management practitioners and end users in the artificial intelligence model's adoption should be boosted.

(v) Lack of human role, explanation metrics, and uncertainty management: Efforts need to be concentrated in these areas amongst other in the future. Moreover, the development of evaluation metrics that can cater prognostics and health management needs is urgently recommended.

(vi) Mostly real case studies were tested: the confidence of prognostics and health management practitioners and end users in the artificial intelligence model's adoption should be increased.

The limitations of this study are stated below:

(i) This review does not classify explainable artificial intelligence methods in term of their nature (post-hoc, local, or global explainability): New insights or patterns could potentially be discovered by applying this classification.

(ii) The review does not explore in detail the subject of explainability metrics: This aspect should be a standalone subject as it is a vast and emerging topic that involves the explainable artificial intelligence methods, human factors, and the proper need for the domain.

Author Contributions: Conceptualization, A.K.M.N.; methodology, A.K.M.N. and V.L.; software, A.K.M.N.; validation, A.K.M.N. and V.L.; formal analysis, A.K.M.N.; investigation, A.K.M.N.; data curation, A.K.M.N.; writing-original draft preparation, A.K.M.N.; writing-review and editing, A.K.M.N. and V.L.; visualization, A.K.M.N.; supervision, S.R.P., M.M. and V.L. All authors have read and agreed to the published version of the manuscript.

Funding: This research was partially funded by Universiti Teknologi Petronas Foundation -YUTP(A.K.M.N., S.R.P., M.M.) and by FONDECYT, project grant number 1200525 (V.L.) from the National Agency for Research and Development (ANID) of the Chilean government under the Ministry of Science, Technology, Knowledge, and Innovation.

Institutional Review Board Statement: Not applicable.

Informed Consent Statement: Not applicable.

Data Availability Statement: The data presented in this study are openly available online at: www.mdpi.com/ethics.github.com/Kamalnor?tab=repositories (accessed on 19 October 2021).

Conflicts of Interest: The authors declare no conflict of interest. 


\section{Appendix A}

Table A1. Analysis results of selected articles.

\begin{tabular}{|c|c|c|c|c|c|c|c|c|c|c|c|}
\hline ID & $\begin{array}{l}\text { Authors and } \\
\text { Year }\end{array}$ & Title & $\begin{array}{l}\text { Publisher, } \\
\text { Publication } \\
\text { Name }\end{array}$ & $\begin{array}{l}\text { PHM } \\
\text { Activity }\end{array}$ & XAI Approach & Performance & $\begin{array}{l}\text { XAI Assist } \\
\text { PHM }\end{array}$ & Metric & Human Role & $\begin{array}{l}\text { Uncertainty } \\
\text { Management }\end{array}$ & Case Study \\
\hline 1 & $\begin{array}{l}{[54]} \\
\text { Wong et al., } \\
2015\end{array}$ & $\begin{array}{l}\text { On equivalence of } \\
\text { FIS and ELM for } \\
\text { interpretable } \\
\text { rule-based } \\
\text { knowledge } \\
\text { representation }\end{array}$ & $\begin{array}{l}\text { IEEE, IEEE } \\
\text { Transactions on } \\
\text { Neural } \\
\text { Networks and } \\
\text { Learning } \\
\text { Systems }\end{array}$ & Diagnostic & $\begin{array}{l}\text { Rule- and } \\
\text { knowledge- } \\
\text { based }\end{array}$ & $\begin{array}{l}\text { Accuracy: } 85.14 \% \\
\text { Good }\end{array}$ & Yes & No & No & No & $\begin{array}{l}\text { Real- } \\
\text { Circulating cooling } \\
\text { water system for } \\
\text { turbine. } \\
\text { (energy sector) }\end{array}$ \\
\hline 2 & $\begin{array}{c}{[55]} \\
\text { Wu et al., } \\
2018\end{array}$ & $\begin{array}{c}\text { K-PdM: } \\
\text { KPI-oriented } \\
\text { machinery } \\
\text { deterioration } \\
\text { estimation } \\
\text { framework for } \\
\text { oredictive } \\
\text { maintenance using } \\
\text { cluster-based } \\
\text { hidden } \\
\text { Markov model }\end{array}$ & $\begin{array}{l}\text { IEEE, } \\
\text { IEEE Access }\end{array}$ & Prognostic & $\begin{array}{l}\text { Rule- and } \\
\text { knowledge- } \\
\text { based }\end{array}$ & $\begin{array}{l}\text { RMSE: } 14.28 \\
\text { Very Good }\end{array}$ & No & No & No & $\begin{array}{l}\text { Probabilistic } \\
\text { state transition } \\
\text { model }\end{array}$ & $\begin{array}{l}\text { Simulated-- } \\
\text { Turbofan engine } \\
\text { (aerospace) }\end{array}$ \\
\hline 3 & $\begin{array}{c}{[56]} \\
\text { Massimo et al., } \\
2018\end{array}$ & $\begin{array}{l}\text { Unsupervised } \\
\text { classification of } \\
\text { multichannel } \\
\text { profile data using } \\
\text { PCA: An } \\
\text { application to an } \\
\text { emission control } \\
\text { system }\end{array}$ & $\begin{array}{l}\text { Elsevier, } \\
\text { Computers and } \\
\text { Industrial } \\
\text { Engineering }\end{array}$ & Diagnostic & $\begin{array}{l}\text { Cluster- } \\
\text { based }\end{array}$ & $\begin{array}{c}\text { MSE: } 2.127 \times 10^{-5} \\
\text { to } 5.809 \times 10^{-3} \\
\text { Very Good }\end{array}$ & Yes & No & Yes & No & $\begin{array}{l}\text { Real-Emission } \\
\text { control system } \\
\text { (automotive, } \\
\text { environment) }\end{array}$ \\
\hline 4 & $\begin{array}{c}{[57]} \\
\text { Mathias et al, } \\
2019\end{array}$ & $\begin{array}{c}\text { Forecasting } \\
\text { remaining useful } \\
\text { life: Interpretable } \\
\text { deep learning } \\
\text { approach via } \\
\text { variational } \\
\text { Bayesian inference } \\
\end{array}$ & $\begin{array}{l}\text { Elsevier, } \\
\text { Decision } \\
\text { Support } \\
\text { Systems }\end{array}$ & Prognostic & $\begin{array}{l}\text { Interpretable } \\
\text { model }\end{array}$ & $\begin{array}{l}\text { MAE: } 13.267 \\
\text { Better than other } \\
\text { methods, } \\
\text { except LSTM }\end{array}$ & No & No & No & $\begin{array}{l}\text { Uncertainty in } \\
\text { model } \\
\text { parameters }\end{array}$ & $\begin{array}{l}\text { Simulated-- } \\
\text { Turbofan engine } \\
\text { (Aerospace) }\end{array}$ \\
\hline 5 & $\begin{array}{l}\text { [58] } \\
\text { Imene et al., } \\
2019\end{array}$ & $\begin{array}{l}\text { Fault isolation in } \\
\text { manufacturing } \\
\text { systems based on } \\
\text { learning algorithm } \\
\text { and fuzzy rule } \\
\text { selection }\end{array}$ & $\begin{array}{l}\text { Springer, } \\
\text { Neural } \\
\text { Computing } \\
\text { and } \\
\text { Applications }\end{array}$ & Diagnostic & $\begin{array}{l}\text { Rule- and } \\
\text { knowledge- } \\
\text { based }\end{array}$ & $\begin{array}{l}\text { Accuracy: } 97.01 \% \\
\text { Very Good }\end{array}$ & Yes & No & No & $\begin{array}{c}\text { Probabilistic } \\
\text { classification by } \\
\text { Bayes } \\
\text { decision rule }\end{array}$ & $\begin{array}{c}\text { Real- } \\
\text { Rotary kiln } \\
\text { (civil engineering) }\end{array}$ \\
\hline
\end{tabular}


Table A1. Cont.

\begin{tabular}{|c|c|c|c|c|c|c|c|c|c|c|c|}
\hline ID & $\begin{array}{l}\text { Authors and } \\
\text { Year }\end{array}$ & Title & $\begin{array}{l}\text { Publisher, } \\
\text { Publication } \\
\text { Name }\end{array}$ & $\begin{array}{l}\text { PHM } \\
\text { Activity }\end{array}$ & XAI Approach & Performance & $\begin{array}{c}\text { XAI Assist } \\
\text { PHM }\end{array}$ & Metric & Human Role & $\begin{array}{l}\text { Uncertainty } \\
\text { Management }\end{array}$ & Case Study \\
\hline 6 & $\begin{array}{l}{[59]} \\
\text { Kerelous et al., } \\
2019\end{array}$ & $\begin{array}{l}\text { Interpretable logic } \\
\text { tree analysis: A } \\
\text { data-driven fault } \\
\text { tree methodology } \\
\text { for causality } \\
\text { analysis }\end{array}$ & $\begin{array}{c}\text { Elsevier, } \\
\text { Expert Systems } \\
\text { with } \\
\text { Applications }\end{array}$ & Diagnostic & LAD & $\begin{array}{l}\text { Mean and standard } \\
\text { errors are less than } \\
2 \% \text { and } 1 \% \\
\text { Very good }\end{array}$ & Yes & No & Yes & $\begin{array}{l}\text { FTA-Expert } \\
\text { opinion }\end{array}$ & $\begin{array}{c}\text { Simulated-- } \\
\text { Actuator system } \\
\text { (manufacturing, } \\
\text { energy, production, } \\
\text { chemical) }\end{array}$ \\
\hline 7 & $\begin{array}{l}\text { [60] } \\
\text { Rajendran } \\
\text { et al., } 2019\end{array}$ & $\begin{array}{c}\text { Unsupervised } \\
\text { wireless spectrum } \\
\text { anomaly detection } \\
\text { with interpretable } \\
\text { features }\end{array}$ & $\begin{array}{c}\text { IEEE, IEEE } \\
\text { Transactions on } \\
\text { Cognitive Com- } \\
\text { munications } \\
\text { and } \\
\text { Networking }\end{array}$ & $\begin{array}{l}\text { Anomaly } \\
\text { detection }\end{array}$ & Autoencoder & $\begin{array}{l}\text { Generally better } \\
\text { than } \\
\text { other tested } \\
\text { methods }\end{array}$ & Yes & No & No & $\begin{array}{l}\text { Probabilistic } \\
\text { classification } \\
\text { error by } \\
\text { discriminator }\end{array}$ & $\begin{array}{l}\text { Real-software } \\
\text { defined radio } \\
\text { spectrum } \\
\text { simulated- } \\
\text { synthetic data } \\
\text { (communication) }\end{array}$ \\
\hline 8 & $\begin{array}{c}{[61]} \\
\text { Wang et al., } \\
2019\end{array}$ & $\begin{array}{c}\text { An attention- } \\
\text { augmented deep } \\
\text { architecture for } \\
\text { hard drive status } \\
\text { monitoring in } \\
\text { large-scale storag } \\
\text { systems }\end{array}$ & $\begin{array}{l}\text { ACM, ACM } \\
\text { Transactions on } \\
\text { Storage }\end{array}$ & $\begin{array}{l}\text { Prognostic, } \\
\text { diagnostic }\end{array}$ & $\begin{array}{l}\text { Attention } \\
\text { mechanism }\end{array}$ & $\begin{array}{c}\text { Prognostic } \\
\text { precision: } \\
94.5-98.3 \% \\
\text { Generally, better } \\
\text { than other methods. } \\
\text { No comparison in } \\
\text { diagnostic }\end{array}$ & $\begin{array}{l}\text { Diag: Yes } \\
\text { Prog: No }\end{array}$ & No & No & No & $\begin{array}{l}\text { Real- } \\
\text { Hard drive } \\
\text { (information } \\
\text { technology) }\end{array}$ \\
\hline 9 & $\begin{array}{c}{[62]} \\
\text { Le et al., } 2019\end{array}$ & $\begin{array}{l}\text { Visualization and } \\
\text { explainable } \\
\text { machine learning } \\
\text { for efficient } \\
\text { manufacturing and } \\
\text { system operations }\end{array}$ & $\begin{array}{c}\text { ASTM, } \\
\text { Smart and } \\
\text { Sustainable } \\
\text { Manufacturing } \\
\text { Systems }\end{array}$ & Diagnostic & Others & $\mathrm{N} / \mathrm{A}^{1}$ & Yes & No & Yes & No & $\begin{array}{l}\text { Simulated- } \\
\text { turbofan } \\
\text { (aerospace) }\end{array}$ \\
\hline 10 & $\begin{array}{c}\text { [63] } \\
\text { Langone et al., } \\
2020\end{array}$ & $\begin{array}{c}\text { Interpretable } \\
\text { anomaly prediction: } \\
\text { Predicting } \\
\text { anomalous } \\
\text { behavior in } \\
\text { industry } 4.0 \\
\text { settings via } \\
\text { regularized logistic } \\
\text { regression tools }\end{array}$ & $\begin{array}{l}\text { Elsevier, } \\
\text { Data and } \\
\text { Knowledge } \\
\text { Engineering }\end{array}$ & $\begin{array}{l}\text { Anomaly } \\
\text { detection }\end{array}$ & $\begin{array}{c}\text { Interpretable } \\
\text { model }\end{array}$ & $\begin{array}{l}\text { Kappa: } 0.4-0.6 \\
\text { AUC: } 0.6-0.8 \\
\text { F1: } 0.3-0.5 \\
\text { PRAUC: } 0.2-0.4 \\
\text { Good }\end{array}$ & Yes & No & No & $\begin{array}{l}\text { Statistical } \\
\text { feature } \\
\text { extraction }\end{array}$ & $\begin{array}{l}\text { Real- } \\
\text { High-pressure } \\
\text { plunger pump } \\
\text { (chemical) }\end{array}$ \\
\hline 11 & $\begin{array}{c}{[64]} \\
\text { Peng et al., } \\
2020\end{array}$ & $\begin{array}{c}\text { A dynamic } \\
\text { structure-adaptive } \\
\text { symbolic approach } \\
\text { for slewing } \\
\text { bearings life } \\
\text { prediction under } \\
\text { variable working } \\
\text { conditions }\end{array}$ & $\begin{array}{c}\text { Sage, } \\
\text { Structural } \\
\text { Health } \\
\text { Monitoring }\end{array}$ & Prognostic & $\begin{array}{c}\text { Interpretable } \\
\text { model }\end{array}$ & $\begin{array}{c}\text { RMSE: } 18.19 \\
\text { Better than } \\
\text { previous methods }\end{array}$ & Yes & No & No & No & $\begin{array}{c}\text { Real- } \\
\text { Slewing bearings } \\
\text { (rotating machinery, } \\
\text { energy, } \\
\text { manufacturing) }\end{array}$ \\
\hline
\end{tabular}


Table A1. Cont.

\begin{tabular}{|c|c|c|c|c|c|c|c|c|c|c|c|}
\hline ID & $\begin{array}{l}\text { Authors and } \\
\text { Year }\end{array}$ & Title & $\begin{array}{c}\text { Publisher, } \\
\text { Publication } \\
\text { Name }\end{array}$ & $\begin{array}{l}\text { PHM } \\
\text { Activity }\end{array}$ & XAI Approach & Performance & $\begin{array}{l}\text { XAI Assist } \\
\text { PHM }\end{array}$ & Metric & Human Role & $\begin{array}{l}\text { Uncertainty } \\
\text { Management }\end{array}$ & Case Study \\
\hline 12 & $\begin{array}{c}{[65]} \\
\text { Ritto et al., } 2020\end{array}$ & $\begin{array}{c}\text { Digital twin, } \\
\text { physics-based } \\
\text { model, and } \\
\text { machine learning } \\
\text { applied to damage } \\
\text { detection in } \\
\text { structures }\end{array}$ & $\begin{array}{l}\text { Elsevier, } \\
\text { Mechanical } \\
\text { Systems and } \\
\text { Signal } \\
\text { Processing }\end{array}$ & Diagnostic & $\begin{array}{l}\text { Interpretable } \\
\text { model }\end{array}$ & $\begin{array}{l}\text { Accuracy: } \\
\text { 74.8-93.3\% } \\
\text { Good }\end{array}$ & No & No & No & No & $\begin{array}{c}\text { Not specified- } \\
\text { Spring mass system } \\
\text { (wind } \\
\text { turbine, energy) }\end{array}$ \\
\hline 13 & $\begin{array}{c}{[66]} \\
\text { Rea et al., } 2020\end{array}$ & $\begin{array}{l}\text { Progress toward } \\
\text { interpretable } \\
\text { machine learning } \\
\text { based disruption } \\
\text { predictors across } \\
\text { tokamaks }\end{array}$ & $\begin{array}{l}\text { Taylor and } \\
\text { Francis, Fusion } \\
\text { Science and } \\
\text { Technology }\end{array}$ & Diagnostic & $\begin{array}{l}\text { Interpretable } \\
\text { model }\end{array}$ & $\mathrm{N} / \mathrm{A}$ & No & No & No & $\begin{array}{l}\text { Physic-based } \\
\text { indicator }\end{array}$ & $\begin{array}{l}\text { Real DIII-D and } \\
\text { JET tokamaks } \\
\text { (energy) }\end{array}$ \\
\hline 14 & $\begin{array}{l}{[67]} \\
\text { Murari et al., } \\
2020\end{array}$ & $\begin{array}{l}\text { Investigating the } \\
\text { physics of tokamak } \\
\text { global stability with } \\
\text { interpretable ML } \\
\text { tools }\end{array}$ & $\begin{array}{l}\text { MDPI, } \\
\text { Applied } \\
\text { Sciences }\end{array}$ & $\begin{array}{l}\text { Anomaly } \\
\text { detection }\end{array}$ & $\begin{array}{l}\text { Mathematic } \\
\text { equation }\end{array}$ & $\begin{array}{l}\text { Success Rate > 90\% } \\
\text { Very Good }\end{array}$ & No & No & No & No & $\begin{array}{c}\text { Type unspecified- } \\
\text { Tokamak } \\
\text { (energy) }\end{array}$ \\
\hline 15 & $\begin{array}{l}{[68]} \\
\text { Zhou et al., } \\
2020\end{array}$ & $\begin{array}{l}\text { Fault diagnosis of } \\
\text { gas turbine based } \\
\text { on partly } \\
\text { interpretable } \\
\text { convolutional } \\
\text { neural networks }\end{array}$ & $\begin{array}{l}\text { Elsevier, } \\
\text { Energy }\end{array}$ & Diagnostic & Tree-based & $\begin{array}{l}\text { Accuracy: } 95.52 \% \\
\text { Better than other } \\
\text { tested methods }\end{array}$ & Yes & No & No & No & $\begin{array}{l}\text { Simulated- } \\
\text { Gas turbine model } \\
\text { (energy) }\end{array}$ \\
\hline 16 & $\begin{array}{l}{[69]} \\
\text { Zhou et al., } \\
2020\end{array}$ & $\begin{array}{l}\text { Addressing noise } \\
\text { and skewness in } \\
\text { interpretable } \\
\text { health-condition } \\
\text { assessment by } \\
\text { learning model } \\
\text { confidence }\end{array}$ & $\begin{array}{l}\text { MDPI, } \\
\text { Sensors }\end{array}$ & Diagnostic & $\begin{array}{l}\text { Rule- and } \\
\text { knowledge- } \\
\text { based }\end{array}$ & $\begin{array}{l}\text { F1 Score: } 0.8005 \\
\text { Very Good }\end{array}$ & No & No & No & No & $\begin{array}{c}\text { Real- } \\
\text { Aircraft structure. } \\
\text { (aerospace) }\end{array}$ \\
\hline 17 & $\begin{array}{c}{[70]} \\
\text { Jianbo et al., } \\
2020\end{array}$ & $\begin{array}{l}\text { Knowledge } \\
\text { extraction and } \\
\text { insertion to deep } \\
\text { belief network for } \\
\text { gearbox fault } \\
\text { diagnosis }\end{array}$ & $\begin{array}{l}\text { Elsevier, } \\
\text { Knowledge- } \\
\text { Based } \\
\text { Systems }\end{array}$ & Diagnostic & $\begin{array}{l}\text { Rule- and } \\
\text { Knowledge- } \\
\text { based }\end{array}$ & $\begin{array}{l}\text { Accuracy: } 92.33 \\
\text { Very Good }\end{array}$ & Yes & No & No & No & $\begin{array}{c}\text { Real- } \\
\text { Gearbox } \\
\text { (manufacturing, } \\
\text { energy, automotive) }\end{array}$ \\
\hline 18 & $\begin{array}{l}{[71]} \\
\text { Conde et al., } \\
2020\end{array}$ & $\begin{array}{l}\text { Isotonic boosting } \\
\text { classification rules }\end{array}$ & $\begin{array}{c}\text { Springer, } \\
\text { Advances in } \\
\text { Data Analysis } \\
\text { and } \\
\text { Classification }\end{array}$ & Diagnostic & $\begin{array}{l}\text { Rule- and } \\
\text { knowledge- } \\
\text { based }\end{array}$ & $\begin{array}{c}\text { Total } \\
\text { Misclassification } \\
\text { Probability (TMP): } \\
0.036-0.164 \\
\text { Good and } \\
\text { comparable to } \\
\text { other methods }\end{array}$ & Yes & No & No & No & $\begin{array}{c}\text { Real- } \\
\text { Induction motor } \\
\text { (manufacturing, } \\
\text { energy, production) }\end{array}$ \\
\hline
\end{tabular}


Table A1. Cont.

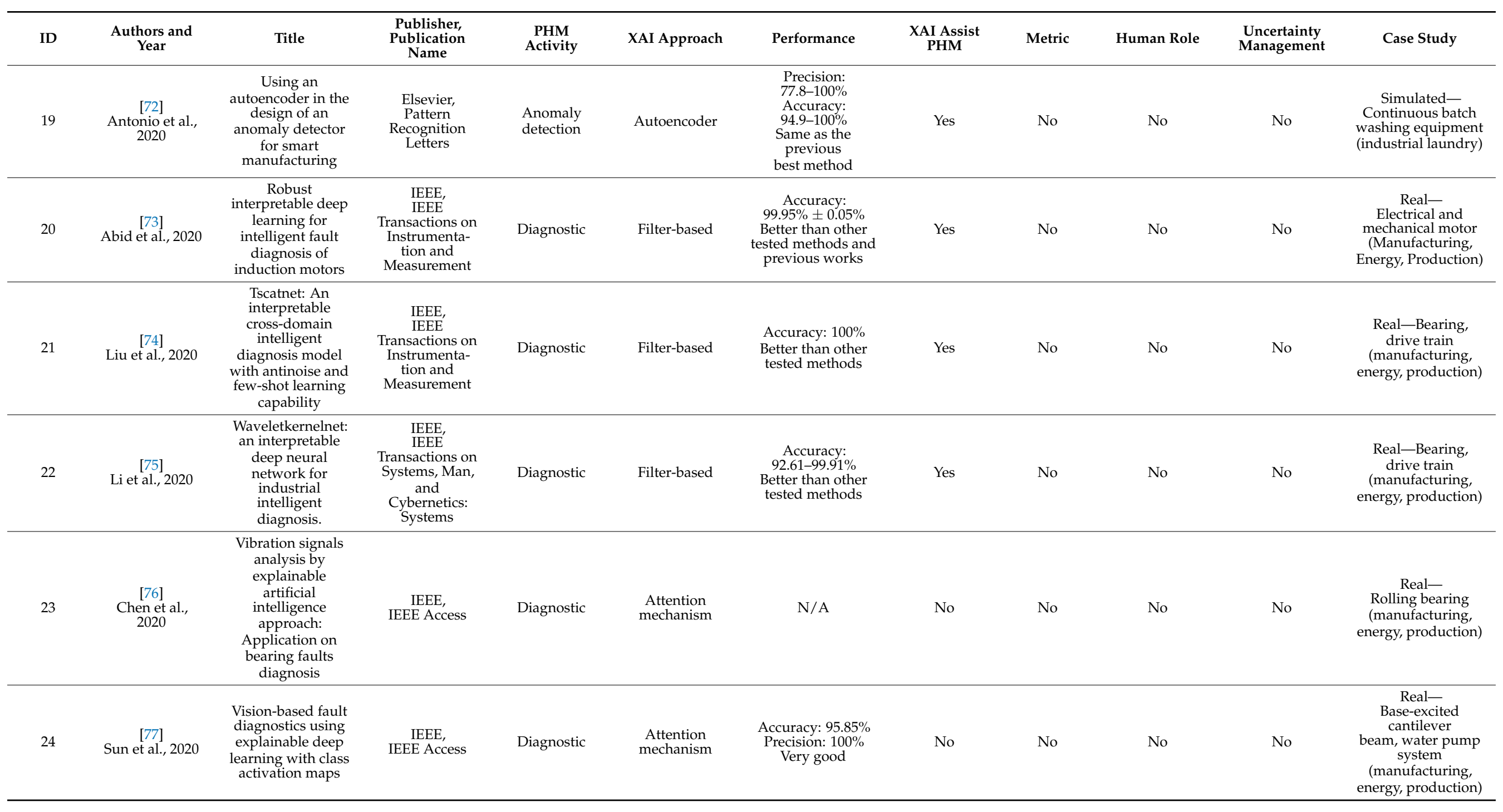


Table A1. Cont.

\begin{tabular}{|c|c|c|c|c|c|c|c|c|c|c|c|}
\hline ID & $\begin{array}{l}\text { Authors and } \\
\text { Year }\end{array}$ & Title & $\begin{array}{l}\text { Publisher, } \\
\text { Publication } \\
\text { Name }\end{array}$ & $\begin{array}{l}\text { PHM } \\
\text { Activity }\end{array}$ & XAI Approach & Performance & $\begin{array}{c}\text { XAI Assist } \\
\text { PHM }\end{array}$ & Metric & Human Role & $\begin{array}{l}\text { Uncertainty } \\
\text { Management }\end{array}$ & Case Study \\
\hline 25 & $\begin{array}{l}{[78]} \\
\text { Oh et al., } 2020\end{array}$ & $\begin{array}{c}\text { VODCA: } \\
\text { Verification of } \\
\text { diagnosis using } \\
\text { CAM-based } \\
\text { approach for } \\
\text { explainable process } \\
\text { monitoring }\end{array}$ & MDPI, Sensors & Diagnostic & $\begin{array}{l}\text { Attention } \\
\text { mechanism }\end{array}$ & $\begin{array}{l}\text { Accuracy: } \\
\text { 78.4-99.5\% } \\
\text { Good }\end{array}$ & Yes & No & No & $\begin{array}{l}\text { True positive } \\
\text { and true } \\
\text { negative } \\
\text { indicators }\end{array}$ & $\begin{array}{l}\text { Simulated- } \\
\text { Ford motor and } \\
\text { real—sapphire } \\
\text { grinding } \\
\text { (automotive, } \\
\text { production) }\end{array}$ \\
\hline 26 & $\begin{array}{c}{[79]} \\
\text { Sreenath et al., } \\
2020\end{array}$ & $\begin{array}{l}\text { Fouling modeling } \\
\text { and prediction } \\
\text { approach for heat } \\
\text { exchangers using } \\
\text { deep learning }\end{array}$ & $\begin{array}{c}\text { Elsevier, } \\
\text { International } \\
\text { Journal of Heat } \\
\text { and Mass } \\
\text { Transfer }\end{array}$ & $\begin{array}{l}\text { Failure } \\
\text { Prediction }\end{array}$ & Model agnostic & $\begin{array}{l}\text { Accuracy: } \\
\text { 99.80-99.92\% } \\
\text { Very good }\end{array}$ & No & No & No & No & $\begin{array}{c}\text { Simulated- } \\
\text { Heat-exchanger } \\
\text { model } \\
\text { (manufacturing, } \\
\text { energy, production) }\end{array}$ \\
\hline 27 & $\begin{array}{c}{[80]} \\
\text { Hong et al., } \\
2020\end{array}$ & $\begin{array}{l}\text { Remaining useful } \\
\text { life prognosis for } \\
\text { turbofan engine } \\
\text { using explainable } \\
\text { deep neural } \\
\text { network with } \\
\text { dimensional } \\
\text { reduction }\end{array}$ & MDPI, Sensors & Prognostic & $\begin{array}{c}\text { Model } \\
\text { Agnostic }\end{array}$ & $\begin{array}{l}\text { RMSE: } 10.41 \\
\text { Very good }\end{array}$ & No & No & No & No & $\begin{array}{l}\text { Simulated-- } \\
\text { Turbofan engine } \\
\text { (aerospace) }\end{array}$ \\
\hline 28 & $\begin{array}{c}{[81]} \\
\text { Grezmak et al., } \\
2020\end{array}$ & $\begin{array}{c}\text { Interpretable } \\
\text { convolutional } \\
\text { neural network } \\
\text { through layer-wise } \\
\text { relevance } \\
\text { propagation for } \\
\text { machine fault } \\
\text { diagnosis }\end{array}$ & $\begin{array}{l}\text { IEEE, } \\
\text { IEEE Sensors } \\
\text { Journal }\end{array}$ & Diagnostic & LRP & $\begin{array}{l}\text { Accuracy: } 100 \% \\
\text { Very good }\end{array}$ & No & No & No & No & $\begin{array}{c}\text { Real- } \\
\text { Induction motor } \\
\text { (manufacturing, } \\
\text { energy, production) }\end{array}$ \\
\hline 29 & $\begin{array}{l}{[82]} \\
\text { Ming et al., } \\
2020\end{array}$ & $\begin{array}{l}\text { ProtoSteer: Steering } \\
\text { deep sequence } \\
\text { model with } \\
\text { prototypes }\end{array}$ & $\begin{array}{c}\text { IEEE, } \\
\text { IEEE } \\
\text { Transactions on } \\
\text { Visualization } \\
\text { and Computer } \\
\text { Graphics }\end{array}$ & Diagnostic & Others & N/A & Yes & No & Yes & No & $\begin{array}{l}\text { Real- } \\
\text { Vehicle fault log } \\
\text { (automotive) }\end{array}$ \\
\hline 30 & $\begin{array}{c}{[83]} \\
\text { Chen et al., } \\
2020\end{array}$ & $\begin{array}{c}\text { Frequency- } \\
\text { temporal-logic- } \\
\text { based bearing fault } \\
\text { diagnosis and fault } \\
\text { interpretation using } \\
\text { Bayesian } \\
\text { optimization } \\
\text { \&ANN }\end{array}$ & $\begin{array}{c}\text { Elsevier, } \\
\text { Mechanical } \\
\text { Systems and } \\
\text { Signal } \\
\text { Processing }\end{array}$ & Diagnostic & Others & $\begin{array}{l}\text { Better error } \\
\text { percentage, error } \\
\text { rate and robustness } \\
\text { than other } \\
\text { tested methods }\end{array}$ & Yes & No & No & No & $\begin{array}{l}\text { Real-Bearings } \\
\text { (manufacturing, } \\
\text { energy, production) }\end{array}$ \\
\hline
\end{tabular}


Table A1. Cont.

\begin{tabular}{|c|c|c|c|c|c|c|c|c|c|c|c|}
\hline ID & $\begin{array}{l}\text { Authors and } \\
\text { Year }\end{array}$ & Title & $\begin{array}{l}\text { Publisher, } \\
\text { Publication } \\
\text { Name }\end{array}$ & $\begin{array}{l}\text { PHM } \\
\text { Activity }\end{array}$ & XAI Approach & Performance & $\begin{array}{c}\text { XAI Assist } \\
\text { PHM }\end{array}$ & Metric & Human Role & $\begin{array}{l}\text { Uncertainty } \\
\text { Management }\end{array}$ & Case Study \\
\hline 31 & $\begin{array}{l}\text { [84] } \\
\text { Steenwinckel } \\
\text { et al., } 2021\end{array}$ & $\begin{array}{c}\text { FLAGS: A } \\
\text { methodology for } \\
\text { adaptive anomaly } \\
\text { detection and root } \\
\text { cause analysis on } \\
\text { sensor data streams } \\
\text { by fusing expert } \\
\text { knowledge with } \\
\text { machine learning }\end{array}$ & $\begin{array}{l}\text { Elsevier, } \\
\text { Future } \\
\text { Generation } \\
\text { Computer } \\
\text { Systems }\end{array}$ & $\begin{array}{l}\text { Anomaly } \\
\text { detection, } \\
\text { diagnostic }\end{array}$ & $\begin{array}{l}\text { Rule- and } \\
\text { knowledge- } \\
\text { based }\end{array}$ & $\begin{array}{l}\text { Accuracy: } 75 \% \\
\text { Good in anomaly } \\
\text { detection, } \\
\text { no result for } \\
\text { diagnostic }\end{array}$ & Yes, for both & No & Yes & $\begin{array}{l}\text { FMEA and } \\
\text { FTA-Expert } \\
\text { opinion }\end{array}$ & $\begin{array}{c}\text { Real-Train } \\
\text { (transportation) }\end{array}$ \\
\hline 33 & $\begin{array}{l}{[86]} \\
\text { Onchis et al., } \\
2021\end{array}$ & $\begin{array}{c}\text { Stable and } \\
\text { explainable deep } \\
\text { learning damage } \\
\text { prediction for } \\
\text { prismatic cantilever } \\
\text { steel beam }\end{array}$ & $\begin{array}{l}\text { Elsevier, } \\
\text { Computers in } \\
\text { Industry }\end{array}$ & Diagnostic & $\begin{array}{c}\text { Model } \\
\text { Agnostic }\end{array}$ & $\begin{array}{l}\text { Accuracy for } 19 \% \\
\text { damage: } 75-92 \% \\
\text { Accuracy for } 43 \% \\
\text { damage: } 85-95 \% \\
\text { Good }\end{array}$ & $\begin{array}{l}\text { Yes, by LIME } \\
\text { only }\end{array}$ & $\begin{array}{l}\text { Stability-fit } \\
\text { compensa- } \\
\text { tion index } \\
\text { (SFC)- } \\
\text { Quality } \\
\text { indicator } \\
\text { of the ex- } \\
\text { planations }\end{array}$ & No & Yes & $\begin{array}{c}\text { Real- } \\
\text { Prismatic } \\
\text { cantilever steel } \\
\text { beam } \\
\text { (civil engineering, } \\
\text { structural } \\
\text { engineering) }\end{array}$ \\
\hline 35 & $\begin{array}{l}\text { [88] } \\
\text { Ding et al., } \\
2021\end{array}$ & $\begin{array}{c}\text { Stationary } \\
\text { subspaces } \\
\text { autoregressive with } \\
\text { exogenous terms } \\
\text { methodology for } \\
\text { degradation trend } \\
\text { estimation of } \\
\text { rolling and slewing } \\
\text { bearings }\end{array}$ & $\begin{array}{l}\text { Elsevier, } \\
\text { Mechanical } \\
\text { Systems and } \\
\text { Signal } \\
\text { Processing }\end{array}$ & Prognostic & Others & $\begin{array}{c}\text { MAE: } 0.0375-0.0414 \\
\text { RMSE: } \\
\text { 0.0482-0.0659 } \\
\text { Better than other } \\
\text { methods and } \\
\text { comparable to } \\
\text { previous works }\end{array}$ & Yes & No & No & No & $\begin{array}{l}\text { Real-- } \\
\text { Rolling and slewing } \\
\text { bearings } \\
\text { (manufacturing, } \\
\text { energy, production) }\end{array}$ \\
\hline
\end{tabular}


Table A2. Excluded articles according to the publication year.

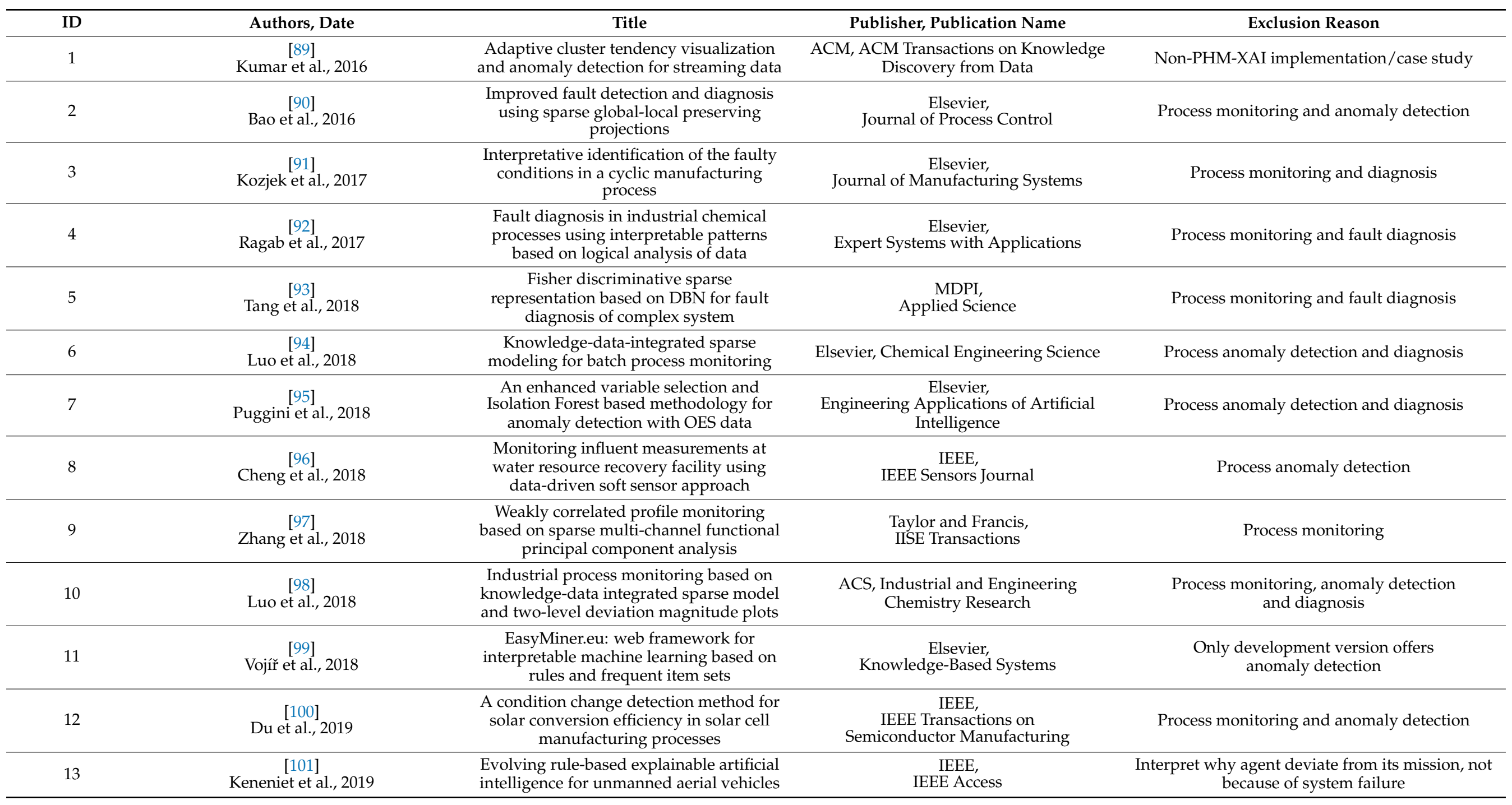


Table A2. Cont.

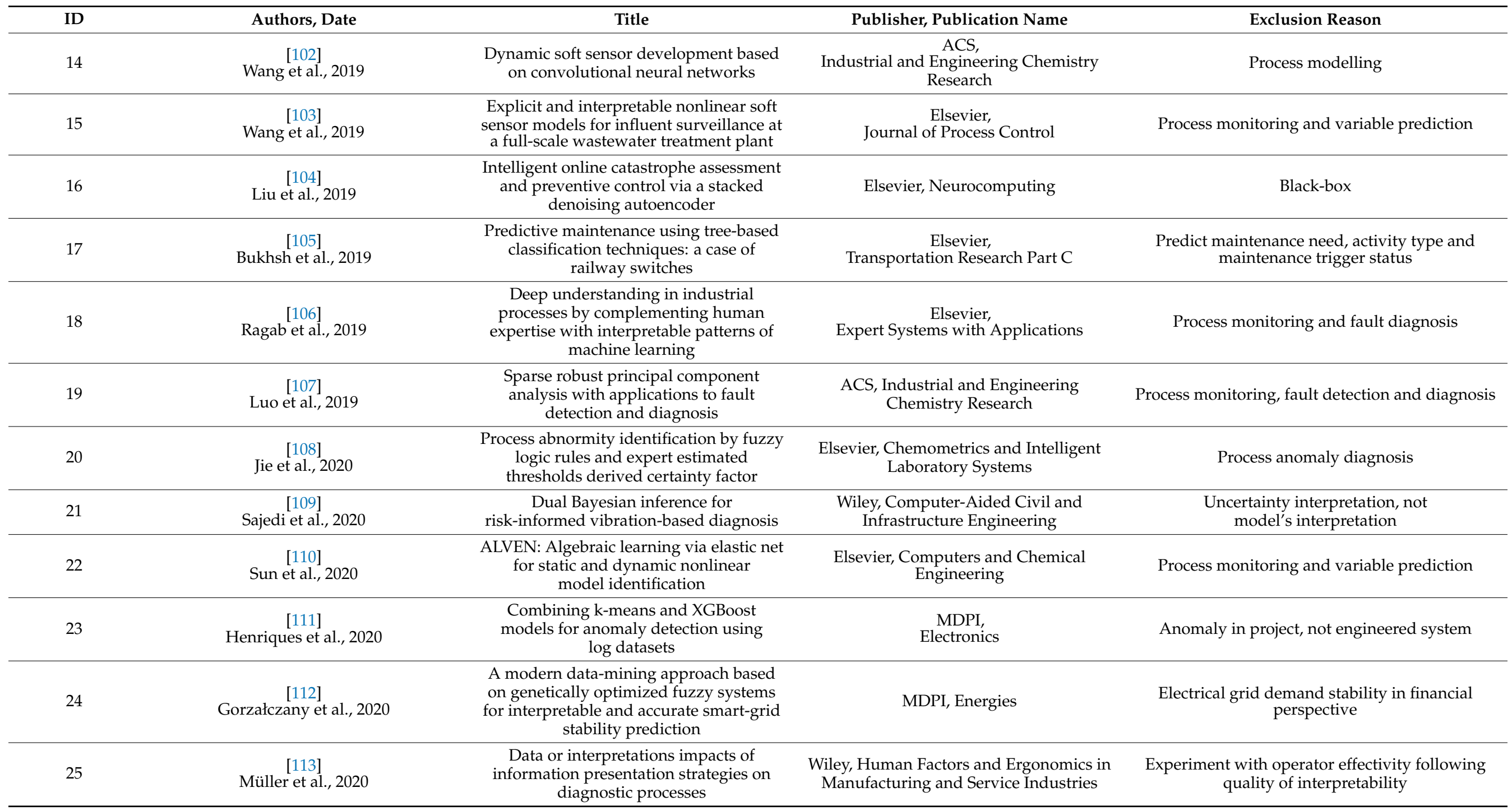


Table A2. Cont.

\begin{tabular}{|c|c|c|c|c|}
\hline ID & Authors, Date & Title & Publisher, Publication Name & Exclusion Reason \\
\hline 26 & $\begin{array}{c}{[114]} \\
\text { Shriram et al., } 2020\end{array}$ & $\begin{array}{l}\text { Least squares sparse principal component } \\
\text { analysis and parallel coordinates for } \\
\text { real-time process monitoring }\end{array}$ & $\begin{array}{l}\text { ACS, Industrial and Engineering } \\
\text { Chemistry Research }\end{array}$ & Process monitoring and diagnosis \\
\hline 27 & $\begin{array}{l}{[115]} \\
\text { Alshraideh et al., } 2020\end{array}$ & $\begin{array}{l}\text { Process control via random forest } \\
\text { classification of profile signals: an } \\
\text { application to a tapping process }\end{array}$ & $\begin{array}{c}\text { Elsevier, } \\
\text { Journal of Manufacturing Processes }\end{array}$ & Process monitoring and anomaly detection \\
\hline 28 & $\begin{array}{c}\text { [116] } \\
\text { Minghua et al., } 2020\end{array}$ & $\begin{array}{l}\text { Diagnosing root causes of intermittent } \\
\text { slow queries in cloud databases }\end{array}$ & $\begin{array}{c}\text { ACM, } \\
\text { Proceedings of the VLDB Endowment }\end{array}$ & $\begin{array}{c}\text { Diagnosing slow query due to lack of resources, } \\
\text { not failure }\end{array}$ \\
\hline 29 & $\begin{array}{l}{[117]} \\
\text { Shaha et al., } 2020\end{array}$ & $\begin{array}{c}\text { Performance prediction and } \\
\text { interpretation of a refuse plastic fuel fired } \\
\text { boiler }\end{array}$ & $\begin{array}{l}\text { IEEE, } \\
\text { IEEE Access }\end{array}$ & Performance prediction \\
\hline 30 & $\begin{array}{c}{[118]} \\
\text { Kovalev et al., } 2020\end{array}$ & $\begin{array}{l}\text { SurvLIME: a method for explaining } \\
\text { machine learning survival models }\end{array}$ & $\begin{array}{c}\text { Elsevier, } \\
\text { Knowledge-Based Systems }\end{array}$ & Medical survival model \\
\hline 31 & $\begin{array}{c}{[119]} \\
\text { Kovalev et al., } 2020\end{array}$ & $\begin{array}{c}\text { A robust algorithm for explaining } \\
\text { unreliable machine learning survival } \\
\text { models using the Kolmogorov.Smirnov } \\
\text { bounds }\end{array}$ & $\begin{array}{l}\text { Elsevier, } \\
\text { Neural Networks }\end{array}$ & Medical survival model \\
\hline 32 & $\begin{array}{l}{[120]} \\
\text { Karn et al., } 2021\end{array}$ & $\begin{array}{c}\text { Cryptomining detection in container } \\
\text { clouds using system calls and explainable } \\
\text { machine learning }\end{array}$ & $\begin{array}{l}\text { IEEE, IEEE Transactions on Parallel and } \\
\text { Distributed Systems }\end{array}$ & Network attack \\
\hline 33 & $\begin{array}{l}\text { [121] } \\
\text { Gyula et al., } 2021\end{array}$ & $\begin{array}{l}\text { Decision trees for informative process } \\
\text { alarm definition and alarm-based fault } \\
\text { classification }\end{array}$ & $\begin{array}{l}\text { Elsevier, Process Safety and } \\
\text { Environmental Protection }\end{array}$ & Process monitoring and anomaly detection \\
\hline 34 & $\begin{array}{c}{[122]} \\
\text { Zaman et al., } 2021\end{array}$ & $\begin{array}{l}\text { Fuzzy heuristics and decision tree for } \\
\text { classification of statistical feature-based } \\
\text { control chart patterns }\end{array}$ & MDPI, Symmetry & Process monitoring and diagnosis \\
\hline 35 & $\begin{array}{c}{[123]} \\
\text { Li et al., } 2021\end{array}$ & $\begin{array}{l}\text { DTDR-ALSTM: Extracting dynamic } \\
\text { time-delays to reconstruct multivariate } \\
\text { data for improving attention-based LSTM } \\
\text { industrial time series prediction models }\end{array}$ & $\begin{array}{c}\text { Elsevier, } \\
\text { Knowledge-Based Systems }\end{array}$ & Process monitoring and variable prediction \\
\hline
\end{tabular}


Table A3. Search strategy.

\section{Database and Date}

XEE

$18 / 02 / 21$
Number of

Papers

Search Field and Keywords

Filters Applied

\section{Using 'Document Title}

1. Document Title: explainable OR Document Title: interpretable, Search within results: diagnostic Document Title: explainable OR Document Title: interpretable, Search within results: prognostic Document Title: explainable OR Document Title: interpretable, Search within results: diagnosis Document Tite: explainable OR Docunent Title. interpretable, Search within results: prognosis Document Title: explainable OR Document Title: interpretable, Search within results: anomaly detection

Document Title: explainable OR Document Title: interpretable, Search within results: remaining useful life Document Title: explainable AI OR Document Title: explainable machine learning OR Document Title: explainable deep learning OR Document Title: XAI, Search within results: prognostic Document Title. explainable AI OR Document Title: explainable machine learning OR Do explainable deep learning OR Document Title: XAI, Search within results: diagnostic

OR Ditle: explainable deep learning OR Document Title: XAI, Search within results: diagnosi

11. Document Title: explainable AI OR Document Title: explainable machine learning OR Document Title: explainable deep learning OR Document Title: XAI, Search within results: prognosis

(learning OR Document Title: explainable deep learning OR Document Title: XAI, Search within results: anomaly detection

13. Document Title: explainable AI OR Document Title: explainable machine learning OR Document Title: explainable deep learning OR Document Title: XAI, Search within results: RUL

14. Document Title: explainable AI OR Document Title: explainable machine learning OR Document Title: explainable deep learning OR Document Title: XAI, Search within results: remaining useful life

table machine learning OR Document Title: interpretable deep learning OR Document Title: XAI, Search within results: diagnostic

16. Document Title: interpretable AI OR Document Title: interpretable machine learning OR Document Title: interpretable deep learning OR Document Title: XAI, Search within results: prognostic

17. Document Title: interpretable AI OR Document Title: interpretable machine learning) OR Document Title interpretable deep learning OR Document Title: XAI, Search within results: prognosis

18. Document Title: interpretable AI OR Document Title: interpretable machine learning) OR Document Title interpretable deep learning OR Document Title: XAI, Search within results: diagnosis

作 interpretable deep learning OR Document Title: XAI, Search within results: anomaly detection

20. Document Title: interpretable AI OR Document Title: interpretable machine learning) OR Document Title:

21. Document Title: interpretable AI OR Document Title: interpretable machine learning) OR Document Title: interpretable deep learning OR Document Title: XAI, Search within results: remaining useful life
Journals, Early Access Article, Specify Year Range: 
Table A3. Cont.

\section{Database and Date}

Number of
Extracted

Papers

\section{Search Field and Keywords}

Filters Applied

\section{Using 'Abstract':}

22. Abstract: explainable AI OR Abstract: explainable machine learning OR Abstract: explainable deep learning OR Abstract: XAI, Search within results: prognostic

23. Abstract: explainable AI OR Abstract: explainable machine learning OR Abstract: explainable deep learning OR Abstract: XAI, Search within results: diagnostic

24. Abstract: explainable AI OR Abstract: explainable machine learning OR Abstract: explainable deep learning OR Abstract: XAI, Searc

25. Abstract: explainable AI OR Abstract: explainable machine learning OR Abstract: explainable deep learning OR

26. Abstract: explainable AI OR Abstract: explainable machine learning OR Abstract: explainable deep learning OR Abstract: XAI, Search within results: anomaly detection

27. Abstract: explainable AI OR Abstract: explainable machine learning OR Abstract: explainable deep learning OR

28. Abstract: explainable AI OR Abstract: explainable machine learning OR Abstract: explainable deep learning OR Abstract: XAI, Search within results: remaining useful life

29. Abstract: interpretable AI OR Abstract: interpretable machine learning) OR Abstract: interpretable deep learning OR Abstract: XAI, Search within results: prognostic

30. Abstract: interpretable AI OR Abstract: interpretable machine learning) OR Abstract: interpretable deep learning OR Abstract: XAI, Search within results: diagnostic

31. Abstract: interpretable AI OR Abstract: interpretable machine learning) OR Abstract: interpretable deep learning OR Abstract: XAI, Search within results: prognosis

32. Abstract: interpretable AI OR Abstract: interpretable machine learning) OR Abstract: interpretable deep learning OR Abstract: XAI, Search within results: diagnosis

33. Abstract: interpretable AI OR Abstract: interpretable machine learning) OR Abstract: interpretable deep learning OR Abstract: XAI, Search within results: anomaly detection

34. Abstract: interpretable AI OR Abstract: interpretable machine learning) OR Abstract: interpretable deep learning

35. OR Abstract: XAI, Search within results: RUL OR Abstract: XAI, Search within results: remaining useful life

Using 'Title, abstract or author-specified keywords':

36. ("explainable" OR "interpretable") AND ("prognostic" OR "diagnostic" OR "prognosis" OR "diagnosis" OR "anomaly detection" OR "RUL" OR "remaining useful life")

37. ("explainable $\mathrm{AI}^{\prime}$ OR "explainable machine learning" OR "explainable deep learning" OR "XAI") AND

Science Direct

("progretable AI" OR "interpretable machine learning" OR "interpretable deep learning" OR "XAI") AND

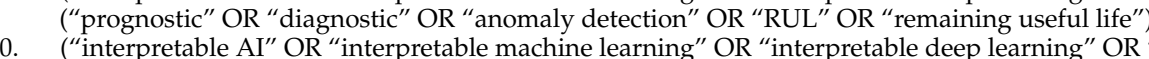

等

Article type: Research Articles, ubject areas: Engineering and 2015-2021 
Table A3. Cont.

Database and Date

\section{Number of \\ Papers}

Search Field and Keywords

Filters Applied

\section{Using 'With all the words'}

41. "explainable" OR "interpretable" AND "prognos"

42. "explainable" OR "interpretable" AND "prognos"

43. "explainable" OR "interpretable" AND "diagnos"

Springer

Link
22/02/21

291

"explainable" OR "interpretable" AND "diagnos"

45. "explainable" OR "interpretable" AND "RUL"

46. "explainable" OR "interpretable" AND "RUL"

47. "explainable" OR interpretable" AND "remaining useful life"

48. "explainable" OR "interpretable" AND "remaining useful life"

49. "explainable "OR "interpretable AND "anomaly detection"

50. "explainable" OR "interpretable" AND "anomaly detection"

\section{Using 'Publication Title, Abstract and Keywords':}

ACM Digital Library

$$
28 / 05 / 21
$$

Scopus
51. Publication Title: explainable or interpretable AND Publication Title: (prognos OR diagnos OR "anomaly detection" OR RUL OR "remaining useful life"

52. Abstract: explainable or interpretable AND Abstract: (prognos OR diagnos OR "anomaly detection" OR RUL OR "remaining useful life"

53. Keywords: explainable or interpretable AND Keywords: (prognos OR diagnos OR “anomaly detection" OR RUL OR "remaining useful life"

54. ("explainable" OR "interpretable") AND ("prognostic" OR "diagnostic" OR "prognosis" OR "diagnosis" OR "anomaly detection" OR "RUL" OR "remaining useful life")
Content Type: Article

Discipline: Computer Science or Engineering,

Show documents published: 2015-2021

\section{Publications: Journal, Content}

Type: Research Article 2015-2021

Limited to: Article, Publication stage: Final, Subject Area: Engineering and Comput Science, Language: English,
from: 
Table A4. Value and classification of the indicated metric.

\begin{tabular}{|c|c|c|c|c|}
\hline Metric & $<50 \%$ & $50-75 \%$ & $75-90 \%$ & $90-100 \%$ \\
\hline Accuracy & Bad & Fair & Good & Very good \\
\hline Precision & Bad & Fair & Good & Very good \\
\hline Metric & $0.00-0.20$ & $0.21-0.40$ & $0.41-0.6$ & $0.61-1.00$ \\
\hline $\mathrm{F} 1$ & Bad & Fair & Good & Very good \\
\hline AUC & Bad & Fair & Good & Very good \\
\hline PRAUC & Bad & Fair & Good & Very good \\
\hline Kappa & Bad & Fair & Good & Very good \\
\hline
\end{tabular}

\section{References}

1. Stone, P.; Brooks, R.; Brynjolfsson, E.; Calo, R.; Etzioni, O.; Hager, G.; Hirschberg, J.; Kalyanakrishnan, S.; Kamar, E.; Kraus, S.; et al. Artificial Intelligence and Life in 2030. One Hundred Year Study on Artificial Intelligence: Report of the 2015-2016 Study Panel; Stanford University: Stanford, CA, USA, 2016. Available online: ai100.stanford.edu/2016-report (accessed on 6 September 2016).

2. Aykroyd, R.; Leiva, V.; Ruggeri, F. Recent developments of control charts, identification of big data sources and future trends of current research. Technol. Forecast. Soc. Chang. 2019, 144, 221-232. [CrossRef]

3. Bughin, J.; Hazan, E.; Ramaswamy, S.; Chui, M.; Allas, T.; Dahlstrom, P.; Henke, N.; Trench, M. Artificial Intelligence: The Next Digital Frontier? McKinsey and Company: Chicago, IL, USA, 2017; pp. 1-80. Available online: apo.org.au/node/210501 (accessed on 24 August 2021).

4. The International Telecommunication Union. Assessing the Economic Impact of Artificial Intelligence, Artificial Intelligence in Service of Business: Creating a Competitive Advantage. St. Petersburg International Economic Forum. 2018. Available online: handle.itu.int/11.1002/pub/81202956-en (accessed on 5 October 2021).

5. Ernst, E.; Merola, R.; Samaan, D. The economics of artificial intelligence: Implications for the future of work. ILO 2018, 9, 1-35. [CrossRef]

6. Rigla, M.; García-Sáez, G.; Pons, B.; Hernando, M.E. Artificial intelligence methodologies and their application to diabetes. J. Diabetes Sci. Technol. 2018, 12, 303-310. [CrossRef]

7. Xin, Z.; Wang, D. Application of artificial intelligence algorithms in image processing. J. Vis. Commun. Image Represent. 2019, 61, 42-49.

8. Palacios, C.A.; Reyes-Suarez, J.A.; Bearzotti, L.A.; Leiva, V.; Marchant, C. Knowledge discovery for higher education student retention based on data mining: Machine learning algorithms and case study in Chile. Entropy 2021, 23, 485. [CrossRef]

9. Bustos, N.; Tello, M.; Droppelmann, G.; Garcia, N.; Feijoo, F.; Leiva, V. Machine learning techniques as an efficient alternative diagnostic tool for COVID-19 cases. Signa Vitae 2022, in press. [CrossRef]

10. Mahdi, E.; Leiva, V.; Mara'Beh, S.; Martin, C. A new approach to predicting cryptocurrency returns based on the gold prices with support vector machines during the COVID-19 pandemic using sensor-related data. Sensors 2021, 21, 6319. [CrossRef]

11. Xu, Z.; Saleh, J. Machine learning for reliability engineering and safety applications: Review of current status and future opportunities. arXiv 2020, arXiv:2008.08221. [CrossRef]

12. Doumari, S.A.; Givi, H.; Dehghani, M.; Montazeri, Z.; Leiva, V.; Guerrero, J.M. A new two-stage algorithm for solving optimization problems. Entropy 2021, 23, 491. [CrossRef]

13. Voulodimos ADoulamis, N.; Doulamis, A.; Protopapadakis, E. Deep learning for computer vision: A brief review. Comput. Intell. Neurosci. 2018, 2018, 7068349. [CrossRef]

14. Linardatos, P.; Papastefanopoulos, V.; Kotsiantis, S. Explainable AI: A review of machine learning interpretability methods. Entropy 2021, 23, 18. [CrossRef] [PubMed]

15. Zhang, S.; Zhang, S.; Wang, B.; Habetler, T.G. Deep learning algorithms for bearing fault diagnostics: A comprehensive review. IEEE Access 2020, 8, 29857-29881. [CrossRef]

16. Lu, S.; Chai, H.; Sahoo, A.; Phung, B.T. Condition monitoring based on partial discharge diagnostics using machine learning methods: A comprehensive state-of-the-art review. IEEE Trans. Dielectr. Electr. Insul. 2020, 27, 1861-1888. [CrossRef]

17. Ellefsen, A.L.; Asøy, V.; Ushakov, S.; Zhang, H. A comprehensive survey of prognostics and health management based on deep learning for autonomous ships. IEEE Trans. Reliab. 2019, 68, 720-740. [CrossRef]

18. Sheppard, J.W.; Kaufman, M.A.; Wilmer, T.J. IEEE standards for prognostics and health management. IEEE Aerosp. Electron. Syst. Mag. 2019, 24, 34-41. [CrossRef]

19. Zhou, J.; Zheng, L.; Wang, Y.; Gogu, C. A Multistage deep transfer learning method for machinery fault diagnostics across diverse working conditions and devices. IEEE Access 2020, 8, 80879-80898. [CrossRef]

20. Khan, S.; Yairi, T. A review on the application of deep learning in system health management. Mech. Syst. Signal Process. 2018, 107, 241-265. [CrossRef] 
21. Aydemir, G.; Paynabar, K. Image-based prognostics using deep learning approach. IEEE Trans. Ind. Inform. 2020, 16, 5956-5964. [CrossRef]

22. Costello, J.J.A.; West, G.M.; McArthur, S.D.J. Machine learning model for event-based prognostics in gas circulator condition monitoring. IEEE Trans. Reliab. 2017, 66, 1048-1057. [CrossRef]

23. Yang, C.; Gunay, B.; Shi, Z.; Shen, W. Machine learning-based prognostics for central heating and cooling plant equipment health monitoring. IEEE Trans. Autom. Sci. Eng. 2021, 18, 346-355. [CrossRef]

24. Sayani, J.K.S.; Lal, B.; Pedapati, S.R. Comprehensive review on various gas hydrate modelling techniques: Prospects and challenges. Arch. Comput. Methods Eng. 2021, in press. [CrossRef]

25. Fan, K.; Hsu, C.; Tsai, D.; He, F.; Cheng, C. Data-driven approach for fault detection and diagnostic in semiconductor manufacturing. IEEE Trans. Autom. Sci. Eng. 2020, 17, 1925-1936. [CrossRef]

26. Li, X.; Zhang, W.; Xu, N.; Ding, Q. Deep learning-based machinery fault diagnostics with domain adaptation across sensors at different places. IEEE Trans. Ind. Electron. 2020, 67, 6785-6794. [CrossRef]

27. Yang, Q.; Jia, X.; Li, X.; Feng, J.; Li, W.; Lee, J. Evaluating feature selection and anomaly detection methods of hard drive failure prediction. IEEE Trans. Reliab. 2021, 70, 749-760. [CrossRef]

28. Tosun, A.B.; Pullara, F.; Becich, M.J.; Taylor, D.L.; Fine, J.L.; Chennubhotla, S.C. Explainable AI (XAI) for anatomic pathology. Adv. Anat. Pathol. 2020, 27, 241-250. [CrossRef] [PubMed]

29. Taylor, J.E.T.; Taylor, G.W. Artificial cognition: How experimental psychology can help generate explainable artificial intelligence. Psychon. Bull. Rev. 2021, 28, 454-475. [CrossRef]

30. Markus, A.; Kors, J.; Rijnbeek, P. The role of explainability in creating trustworthy artificial intelligence for health care: A comprehensive survey of the terminology, design choices, and evaluation strategies. arXiv 2020, arXiv:2007.15911. [CrossRef]

31. Jiménez-Luna, J.; Grisoni, F.; Schneider, G. Drug discovery with explainable artificial intelligence. Nat. Mach. Intell. 2020 2, 573-584. [CrossRef]

32. Barredo, A.; Díaz, N.; Del Ser, J.; Bennetot, A.; Tabik, S.; Barbado, A.; Garcia, S.; Gil-Lopez, S.; Molina, D.; Benjamins, R.; et al. Explainable artificial intelligence (XAI): Concepts, taxonomies, opportunities and challenges toward responsible AI. Inf. Fusion 2020, 58, 82-115. [CrossRef]

33. Payrovnaziri, S.N.; Chen, Z.; Rengifo-Moreno, P.; Miller, T.; Bian, J.; Chen, J.H.; Liu, X.; He, Z. Explainable artificial intelligence models using real-world electronic health record data: A systematic scoping review. J. Am. Med. Inform. Assoc. 2020, 27, 1173-1185. [CrossRef]

34. Stepin, I.; Alonso, J.; Catala, A.; Pereira-Farina, M. A survey of contrastive and counterfactual explanation generation methods for explainable artificial intelligence. IEEE Access 2021, 9, 11974-12001. [CrossRef]

35. Bussmann, N.; Giudici, P.; Marinelli, D.; Papenbrock, J. Explainable AI in fintech risk management. Front. Artif. Intell. 2020, 3, 26. [CrossRef] [PubMed]

36. Tjoa, E.; Guan, C. A survey on explainable artificial intelligence (XAI): Toward medical XAI. IEEE Trans. Neural Netw. Learn. Syst. 2021, 32, 4793-4813. [CrossRef]

37. Streich, J.; Romero, J.; Gazolla, J.; Kainer, D.; Cliff, A.; Prates, E.; Brown, J.B.; Khoury, S.; Tuskan, G.A.; Garvin, M.; et al. Can exascale computing and explainable artificial intelligence applied to plant biology deliver on the United Nations sustainable development goals? Curr. Opin. Biotechnol. 2020, 61, 217-225. [CrossRef] [PubMed]

38. Adadi, A.; Berrada, M. Peeking inside the black-box: A survey on explainable artificial intelligence (XAI). IEEE Access 2018, 6, 52138-52160. [CrossRef]

39. Chen, K.; Hwu, T.; Kashyap, H.J.; Krichmar, J.L.; Stewart, K.; Xing, J.; Zou, X. Neurorobots as a means toward neuroethology and explainable AI. Front. Neurorobot. 2020, 14, 570308. [CrossRef] [PubMed]

40. Xu, F.; Uszkoreit, H.; Du, Y.; Fan, W.; Zhao, D.; Zhu, J. Explainable AI: A brief survey on history, research areas, approaches and challenges. In Natural Language Processing and Chinese Computing. NLPCC 2019; Tang, J., Kan, M.Y., Zhao, D., Li, S., Zan, H., Eds.; Springer: Cham, Switzerland, 2019; Volume 11839, pp. 563-574.

41. Molnar, C. Interpretable Machine Learning. A Guide for Making Black Box Models Explainable. 2019. Available online: https:/ / christophm.github.io/interpretable-ml-book/ (accessed on 17 October 2021).

42. Gianfagna, L.; Di Cecco, A. Model-agnostic methods for XAI. In Explainable AI with Python; Springer: Cham, Switzerland, 2021. [CrossRef]

43. Page, M.J.; McKenzie, J.E.; Bossuyt, P.M.; Boutron, I.; Hoffmann, T.C.; Mulrow, C.D.; Shamseer, L.; Tetzlaff, J.M.; Akl, E.A.; Brennan, S.E.; et al. The PRISMA 2020 statement: An updated guideline for reporting systematic reviews. PLoS Med. 2021, 18, e1003583. [CrossRef] [PubMed]

44. Xing, M.; Yan, X.; Sun, X.; Wang, S.; Zhou, M.; Zhu, B.; Kuai, L.; Liu, L.; Luo, Y.; Li, X.; et al. Fire needle therapy for moderatesevere acne: A PRISMA systematic review and meta-analysis of randomized controlled trials. Complement. Ther. Med. 2019, 44, 253-260. [CrossRef]

45. Li, T.; Hua, F.; Dan, S.; Zhong, Y.; Levey, C.; Song, Y. Reporting quality of systematic review abstracts in operative dentistry: An assessment using the PRISMA for Abstracts guidelines. J. Dent. 2020, 102, 103471. [CrossRef] [PubMed]

46. Lundberg, S.M.; Erion, G.; Chen, H.; DeGrave, A.; Prutkin, J.M.; Nair, B.; Katz, R.; Himmelfarb, J.; Bansal, N.; Lee, S.-I. From local explanations to global understanding with explainable AI for trees. Nat. Mach. Intell. 2020, 2, 56-67. [CrossRef] 
47. Verweij, G.; Rao, A.; Woods, J. Sizing the Prize: What's the Real Value of AI for Your Business and How Can You Capitalise? Available online: www.pwc.com/AI (accessed on 21 June 2017).

48. Brock, D.C. Learning from artificial intelligence's previous awakenings: The history of expert systems. AI Mag. 2018, 39, 3-15. [CrossRef]

49. Itti, L.; Koch, C.; Niebur, E. A model of saliency-based visual attention for rapid scene analysis. IEEE Trans. Pattern Anal. Mach. Intell. 2002, 20, 1254-1259. [CrossRef]

50. Kamal, A.; Pedapati, S.R.; Muhammad, M. Reliability engineering applications in electronic, software, nuclear and aerospace industries: A 20 year review (2000-2020). Ain Shams Eng. J. 2021, 12, 3009-3019.

51. Zhou, J.; Gandomi, A.H.; Chen, F.; Holzinger, A. Evaluating the quality of machine learning explanations: A survey on methods and metrics. Electronics 2021, 10, 593. [CrossRef]

52. Martin, K.; Liret, A.; Wiratunga, N.; Owusu, G.; Kern, M. Evaluating explainability methods intended for multiple stakeholders. Künstliche Intell. 2021, 35, 397-411. [CrossRef]

53. Holzinger, A.; Carrington, A.; Müller, H. Measuring the quality of explanations: The system causability scale (SCS). Künstliche Intell. 2020, 34, 193-198. [CrossRef]

54. Wong, S.Y.; Yap, K.S.; Yap, H.J.; Tan, S.C.; Chang, S.W. On equivalence of FIS and ELM for interpretable rule-based knowledge representation. IEEE Trans. Neural Netw. Learn. Syst. 2015, 26, 1417-1430. [CrossRef]

55. Wu, Z.; Luo, H.; Yang, Y.; Lv, P.; Zhu, X.; Ji, Y.; Wu, B. K-PdM: KPI-oriented machinery deterioration estimation framework for predictive maintenance using cluster-based hidden Markov model. IEEE Access 2018, 6, 41676-41687. [CrossRef]

56. Pacella, M. Unsupervised classification of multichannel profile data using PCA: An application to an emission control system. Comput. Ind. Eng. 2018, 122, 161-169. [CrossRef]

57. Kraus, M.; Feuerriegel, S. Forecasting remaining useful life: Interpretable deep learning approach via variational Bayesian inferences. Decis. Support Syst. 2019, 125, 113100. [CrossRef]

58. Djelloul, I.; Sari, Z.; Souier, M. Fault isolation in manufacturing systems based on learning algorithm and fuzzy rule selection. Neural Comput. Appl. 2019, 31, 3211-3225. [CrossRef]

59. Waghen, K.; Ouali, M.S. Interpretable logic tree analysis: A data-driven fault tree methodology for causality analysis. Expert Syst. Appl. 2019, 136, 376-391. [CrossRef]

60. Rajendran, S.; Meert, W.; Lenders, V.; Pollin, S. Unsupervised wireless spectrum anomaly detection with interpretable features. IEEE Trans. Cogn. Commun. Netw. 2019, 5, 637-647. [CrossRef]

61. Wang, J.; Bao, W.; Zheng, L.; Zhu, X.; Yu, P.S. An attention-augmented deep architecture for hard drive status monitoring in large-scale storage systems. ACM Trans. Storage 2019, 15, 21. [CrossRef]

62. Le, D.; Vung, P.; Nguyen, H.; Dang, T. Visualization and explainable machine learning for efficient. Manuf. Syst. Oper. 2019, 3, 20190029.

63. Langone, R.; Cuzzocrea, A.; Skantzos, N. Interpretable anomaly prediction: Predicting anomalous behavior in industry 4.0 settings via regularized logistic regression tools. Data Knowl. Eng. 2020, 130, 101850. [CrossRef]

64. Ding, P.; Jia, M.; Wang, H. A dynamic structure-adaptive symbolic approach for slewing bearings' life prediction under variable working conditions. Struct. Health Monit. 2020, 20, 273-302. [CrossRef]

65. Ritto, T.G.; Rochinha, F. Digital twin, physics-based model, and machine learning applied to damage detection in structures. Mech. Syst. Signal Process. 2021, 155, 107614. [CrossRef]

66. Rea, C.; Montes, K.; Pau, A.; Granetz, R.; Sauter, O. Progress toward interpretable machine learning-based disruption predictors across tokamaks progress toward interpretable machine learning-based disruption predictors across tokamaks. Fusion Sci. Technol. 2020, 76, 912-924. [CrossRef]

67. Murari, A.; Peluso, E.; Lungaroni, M.; Rossi, R.; Gelfusa, M. Investigating the physics of tokamak global stability with interpretable machine learning tools. Appl. Sci. 2020, 10, 6683. [CrossRef]

68. Zhou, D.; Yao, Q.; Wu, H.; Ma, S.; Zhang, H. Fault diagnosis of gas turbine based on partly interpretable convolutional neural networks. Energy 2020, 200, 117467. [CrossRef]

69. Zhou, Y.; Hong, S.; Shang, J.; Wu, M.; Wang, Q.; Li, H.; Xie, J. Addressing noise and skewness in interpretable health-condition assessment by learning model confidence. Sensors 2020, 20, 7307. [CrossRef]

70. Yu, J.; Liu, G. Knowledge extraction and insertion to deep belief network for gearbox fault diagnosis. Knowl. Based Syst. 2020, 197, 105883. [CrossRef]

71. Conde, D.; Fernández, M.A.; Rueda, C.; Salvador, B. Isotonic boosting classification rules. Adv. Data Anal. Classif. 2021, 15, 289-313. [CrossRef]

72. Alfeo, A.L.; Cimino, M.G.C.A.; Manco, G.; Ritacco, E.; Vaglini, G. Using an autoencoder in the design of an anomaly detector for smart manufacturing. Pattern Recognit. Lett. 2020, 136, 272-278. [CrossRef]

73. Abid, F.B.; Sallem, M.; Braham, A. Robust interpretable deep learning for intelligent fault diagnosis of induction motors. IEEE Trans. Instrum. Meas. 2020, 69, 3506-3515. [CrossRef]

74. Liu, C.; Qin, C.; Shi, X.; Wang, Z.; Zhang, G.; Han, Y. TScatNet: An interpretable cross-domain intelligent diagnosis model with antinoise and few-shot learning capability. IEEE Trans. Instrum. Meas. 2021, 70, 3506110. [CrossRef]

75. Li, T.; Zhao, Z.; Sun, C.; Chetng, L.; Chen, X.; Yan, R.; Gao, R.X. WaveletKernelNet: An interpretable deep neural network for industrial intelligent diagnosis. IEEE Trans. Syst. Man Cybern. Syst. 2021, in press. [CrossRef] 
76. Chen, H.Y.; Lee, C.H. Vibration signals analysis by explainable artificial intelligence (XAI) approach: Application on bearing faults diagnosis. IEEE Access 2020, 8, 134246-134256. [CrossRef]

77. Sun, K.H.; Huh, H.; Tama, B.A.; Lee, S.Y.; Jung, J.H.; Lee, S. Vision-based fault diagnostics using explainable deep learning with class activation maps. IEEE Access 2020, 8, 129169-129179. [CrossRef]

78. Oh, C.; Jeong, J. VODCA: Verification of diagnosis using cam-based approach for explainable process monitoring. Sensors 2020, 20, 6858. [CrossRef]

79. Sundar, S.; Rajagopal, M.; Zhao, H.; Kuntumalla, G.; Meng, Y.; Chang, H.; Shao, C.; Ferreira, P.; Miljkovic, N.; Sinha, S.; et al. Fouling modeling and prediction approach for heat exchangers using deep learning. Int. J. Heat Mass Transf. 2020, $159,120112$. [CrossRef]

80. Hong, C.W.; Lee, C.; Lee, K.; Ko, M.S.; Kim, D.E.; Hur, K. Remaining useful life prognosis for turbofan engine using explainable deep neural networks with dimensionality reduction. Sensors 2020, 20, 6626. [CrossRef]

81. Grezmak, J.; Zhang, J.; Wang, P.; Loparo, K.A.; Gao, R.X. Interpretable convolutional neural network through layer-wise relevance propagation for machine fault diagnosis. IEEE Sens. J. 2020, 20, 3172-3181. [CrossRef]

82. Ming, Y.; Xu, P.; Cheng, F.; Qu, H.; Ren, L. ProtoSteer: Steering deep sequence model with prototypes. IEEE Trans. Vis. Comput. Graph. 2020, 26, 238-248. [CrossRef]

83. Chen, G.; Liu, M.; Chen, J. Frequency-temporal-logic-based bearing fault diagnosis and fault interpretation using Bayesian optimization with Bayesian neural networks. Mech. Syst. Signal Process. 2020, 145, 106951. [CrossRef]

84. Steenwinckel, B.; De Paepe, D.; Vanden Hautte, S.; Heyvaert, P.; Bentefrit, M.; Moens, P.; Dimou, A.; Bossche, B.V.D.; De Turck, F.; Van Hoecke, S.; et al. FLAGS: A methodology for adaptive anomaly detection and root cause analysis on sensor data streams by fusing expert knowledge with machine learning. Future Gener. Comput. Syst. 2021, 116, 30-48. [CrossRef]

85. Zhang, D.; Chen, Y.; Guo, F.; Karimi, H.R.; Dong, H.; Xuan, Q. A new interpretable learning method for fault diagnosis of rolling bearings. IEEE Trans. Instrum. Meas. 2021, 70, 3507010. [CrossRef]

86. Onchis, D.; Gillich, G. Stable and explainable deep learning damage prediction for prismatic cantilever steel beam. Comput. Ind. 2021, 125, 103359. [CrossRef]

87. Kim, M.S.; Yun, J.P.; Park, P. an explainable convolutional neural network for fault diagnosis in linear motion guide. IEEE Trans. Ind. Inform. 2021, 17, 4036-4045. [CrossRef]

88. Ding, P.; Jia, M.; Yan, X. Stationary subspaces-vector autoregressive with exogenous terms methodology for degradation trend estimation of rolling and slewing bearings. Mech. Syst. Signal Process. 2021, 150, 107293. [CrossRef]

89. Kumar, D.; Bezdek, J.; Rajasegarar, S.; Palaniswami, M.; Leckie, C.; Chan, J.; Gubbi, J. Adaptive cluster tendency visualization and anomaly detection for streaming data. ACM Trans. Knowl. Discov. Data 2016, 11, 24. [CrossRef]

90. Bao, S.; Luo, L.; Mao, J. Improved fault detection and diagnosis using sparse global-local preserving projections. J. Process Control 2016, 47, 121-135. [CrossRef]

91. Kozjek, D.; Vrabič, R.; Kralj, D.; Butala, P. Interpretative identification of the faulty conditions in a cyclic manufacturing process. J. Manuf. Syst. 2017, 43, 214-224. [CrossRef]

92. Ragab, A.; Koujok, M.; Poulin, B.; Amazouz, M.; Yacout, S. Fault diagnosis in industrial chemical processes using interpretable patterns based on logical analysis of data. Expert Syst. Appl. 2017, 95, 368-383. [CrossRef]

93. Tang, Q.; Chai, Y.; Qu, J.; Ren, H. Fisher discriminative sparse representation based on DBN for fault diagnosis of complex system. Appl. Sci. 2018, 8, 795. [CrossRef]

94. Luo, L.; Bao, S. Knowledge-data-integrated sparse modeling for batch process monitoring. Chem. Eng. Sci. 2018, 189, 221-232. [CrossRef]

95. Puggini, L.; Mcloone, S. An enhanced variable selection and isolation forest based methodology for anomaly detection with OES data. Eng. Appl. Artif. Intell. 2018, 67, 126-135. [CrossRef]

96. Cheng, T.; Harrou, F.; Sun, Y.; Leiknes, T. Monitoring influent measurements at water resource recovery facility using data-driven soft sensor approach. IEEE Sens. J. 2019, 19, 42-352. [CrossRef]

97. Zhang, C.; Yan, H.; Lee, S.; Shi, J. Weakly correlated profile monitoring based on sparse multi-channel functional principal component analysis. IISE Trans. 2018, 50, 878-891. [CrossRef]

98. Luo, L.; Bao, S.; Mao, J.; Ding, Z. Industrial process monitoring based on knowledge-data integrated sparse model and two-level deviation magnitude plots. Ind. Eng. Chem. Res. 2018, 57, 611-622. [CrossRef]

99. Vojíř, S.; Zeman, V.; Kuchař, J.; Kliegr, T. EasyMiner.eu: Web framework for interpretable machine learning based on rules and frequent itemsets. Knowl. Based Syst. 2018, 150, 111-115. [CrossRef]

100. Du, J.; Zhang, X.; Shi, J. A condition change detection method for solar conversion efficiency in solar cell manufacturing processes. IEEE Trans. Semicond. Manuf. 2019, 32, 82-92. [CrossRef]

101. Keneni, B.M.; Kaur, D.; Al Bataineh, A.; Devabhaktuni, V.K.; Javaid, A.Y.; Zaientz, J.D.; Marinier, R.P. Evolving rule-based explainable artificial intelligence for unmanned aerial vehicles. IEEE Access 2019, 7, 17001-17016. [CrossRef]

102. Wang, K.; Shang, C.; Liu, L.; Jiang, Y.; Huang, D.; Yang, F. Dynamic soft sensor development based on convolutional neural networks. Ind. Eng. Chem. Res. 2019, 58, 11521-11531. [CrossRef]

103. Wang, X.; Kvaal, K.; Ratnaweera, H. Explicit and interpretable nonlinear soft sensor models for influent surveillance at a full-scale wastewater treatment plant. J. Process Control 2019, 77, 1-6. [CrossRef] 
104. Liu, Y.; Zhai, M.; Jin, J.; Song, A.; Lin, J.; Wu, Z.; Zhao, Y. Intelligent online catastrophe assessment and preventive control via a stacked denoising autoencoder. Neurocomputing 2019, 380, 306-320. [CrossRef]

105. Bukhsh, Z.; Saeed, A.; Stipanovic, I.; Dorée, A. Predictive maintenance using tree-based classification techniques: A case of railway switches. Transp. Res. Part C 2019, 101, 35-54. [CrossRef]

106. Ragab, A.; El Koujok, M.; Ghezzaz, H.; Amazouz, M.; Ouali, M.; Yacout, S. Deep understanding in industrial processes by complementing human expertise with interpretable patterns of machine learning. Expert Syst. Appl. 2019, 122, 388-405. [CrossRef]

107. Luo, L.; Bao, S.; Tong, C. Sparse robust principal component analysis with applications to fault detection and diagnosis. Ind. Eng. Chem. Res. 2019, 58, 1300-1309. [CrossRef]

108. Yuan, J.; Zhang, S.; Wang, S.; Wang, F.; Zhao, L. Process abnormity identification by fuzzy logic rules and expert estimated thresholds derived certainty factor. Chemom. Intell. Lab. Syst. 2020, 209, 104232. [CrossRef]

109. Sajedi, S.; Liang, X. Dual Bayesian inference for risk-informed vibration-based damage diagnosis. Comput. Aided Civ. Infrastruct. Eng. 2020, 36, 1168-1184. [CrossRef]

110. Sun, W.; Braatz, R. ALVEN: Algebraic learning via elastic net for static and dynamic nonlinear model identification. Comput. Chem. Eng. 2020, 143, 107103. [CrossRef]

111. Henriques, J.; Caldeira, F.; Cruz, T.; Simões, P. Combining k-means and XGBoost models for anomaly detection using log datasets. Electronics 2020, 9, 1164. [CrossRef]

112. Gorzałczany, M.B.; Piekoszewski, J.; Rudziński, F. A modern data-mining approach based on genetically optimized fuzzy systems for interpretable and accurate smart-grid stability prediction. Energies 2020, 13, 2559. [CrossRef]

113. Müller, R.; Gögel, C.; Bönsel, R. Data or interpretations: Impacts of information presentation strategies on diagnostic processes. Hum. Factors Ergon. Manuf. 2020, 30, 266-281. [CrossRef]

114. Gajjar, S.; Kulahci, M.; Palazoglu, A. Least squares sparse principal component analysis and parallel coordinates for real-time process monitoring. Ind. Eng. Chem. Res. 2020, 59, 15656-15670. [CrossRef]

115. Alshraideh, H.; del Castillo, E.; Gil Del Val, A. Process control via random forest classification of profile signals: An application to a tapping process. J. Manuf. Process. 2020, 58, 736-748. [CrossRef]

116. Ma, M.; Yin, Z.; Zhang, S.; Wang, S.; Zheng, C.; Jiang, X.; Minghua, M.; Luo, C.; Li, Y.; Qiu, N.; et al. Diagnosing root causes of intermittent slow queries in cloud databases. Proc. VLDB Endow. 2020, 13, 1176-1189. [CrossRef]

117. Shaha, P.; Singamsetti, M.S.; Tripathy, B.K.; Srivastava, G.; Bilal, M.; Nkenyereye, L. Performance prediction and interpretation of a refuse plastic fuel fired boiler. IEEE Access 2020, 8, 117467-117482. [CrossRef]

118. Kovalev, M.S.; Utkin, L.V.; Kasimov, E.M. SurvLIME: A method for explaining machine learning survival models. Knowl. Based Syst. 2020, 203, 106164. [CrossRef]

119. Kovalev, M.; Utkin, L. A robust algorithm for explaining unreliable machine learning survival models using the KolmogorovSmirnov bounds. arXiv 2020, arXiv:2005.02249.

120. Karn, R.R.; Kudva, P.; Huang, H.; Suneja, S.; Elfadel, I.M. Cryptomining detection in container clouds using system calls and explainable machine learning. IEEE Trans. Parallel Distrib. Syst. 2021, 32, 674-691. [CrossRef]

121. Dorgo, G.; Palazoglu, A.; Abonyi, J. Decision trees for informative process alarm definition and alarm-based fault classification. Process Saf. Environ. Prot. 2021, 149, 312-324. [CrossRef]

122. Zaman, M.; Hassan, A. Fuzzy heuristics and decision tree for classification of statistical feature-based control chart patterns. Symmetry 2021, 13, 110. [CrossRef]

123. Li, J.; Yang, B.; Li, H.; Wang, Y.; Qi, C.; Liu, Y. DTDR-ALSTM: Extracting dynamic time-delays to reconstruct multivariate data for improving attention-based LSTM industrial time series prediction models. Knowl. Based Syst. 2021, 211, 106508. [CrossRef] 